\title{
Energy and Dynamics of Caveolae Trafficking
}

\author{
Claudia Matthaeus* and Justin W. Taraska* \\ Biochemistry and Biophysics Center, National Heart, Lung and Blood Institute, National Institutes of Health, Bethesda, MD, \\ United States
}

\section{OPEN ACCESS}

Edited by: David Charles Gershlick, University of Cambridge, United Kingdom

Reviewed by: Christophe Lamaze, Institut Curie, France Asier Echarri,

Spanish National Centre for Cardiovascular Research, Spain

*Correspondence: Claudia Matthaeus claudia.matthaeus@nih.gov Justin W. Taraska

justin.taraska@nih.gov

Specialty section: This article was submitted to Membrane Traffic,

a section of the journal Frontiers in Cell and Developmental

Biology

Received: 06 October 2020 Accepted: 21 December 2020 Published: 21 January 2021

Citation:

Matthaeus C and Taraska JW (2021) Energy and Dynamics of Caveolae Trafficking.

Front. Cell Dev. Biol. 8:614472. doi: 10.3389/fcell.2020.614472
Caveolae are 70-100 nm diameter plasma membrane invaginations found in abundance in adipocytes, endothelial cells, myocytes, and fibroblasts. Their bulb-shaped membrane domain is characterized and formed by specific lipid binding proteins including Caveolins, Cavins, Pacsin2, and EHD2. Likewise, an enrichment of cholesterol and other lipids makes caveolae a distinct membrane environment that supports proteins involved in cell-type specific signaling pathways. Their ability to detach from the plasma membrane and move through the cytosol has been shown to be important for lipid trafficking and metabolism. Here, we review recent concepts in caveolae trafficking and dynamics. Second, we discuss how ATP and GTP-regulated proteins including dynamin and EHD2 control caveolae behavior. Throughout, we summarize the potential physiological and cell biological roles of caveolae internalization and trafficking and highlight open questions in the field and future directions for study.

\section{Keywords: caveolae, caveolin, dynamin, EHD2, membrane trafficking, lipid trafficking}

\section{INTRODUCTION}

Caveolae are $70-100 \mathrm{~nm}$ diameter sized plasma membrane invaginations that form bulb shape invaginations into the cytosol (Figure 1). They are found in a variety of cell types including adipocytes, endothelial cells, muscle cells, fibroblasts, and astrocytes (Cameron et al., 1997; Parton, 2003; Parton and Del Pozo, 2013; Parton et al., 2018; Yan et al., 2019). The plasma membranes of endothelial, muscle, and fat cells are packed with caveolae, suggesting an important role in specialized functions including homeostasis and metabolism. Caveolae also comprise a specific lipid environment containing large amounts of cholesterol, sphingomyelin, and ceramides (Graf et al., 1999; Parton et al., 2020b; Zhou et al., 2020). These lipids accumulate in caveolae, providing a reservoir for these molecules (Hubert et al., 2020b). Therefore, these organelles serve as unique scaffolds for plasma membrane proteins involved in signaling pathways creating unique cell-type specific protein signaling domains. Caveolae are also known to participate in cellular lipid and fatty acid uptake (Pilch and Liu, 2011; Pilch et al., 2011), endothelial transcytosis of large molecules (Frank et al., 2009; Cheng and Nichols, 2016), regulation of the endothelial NO synthase (Förstermann and Sessa, 2012), neurovascular coupling (Chow et al., 2020), viral internalization (Pelkmans et al., 2001; Xing et al., 2020), and pigmentation in melanocytes (Domingues et al., 2020). Furthermore, under some cellular membrane tension regimes caveolae can group into larger clusters at the plasma membrane termed caveolae rosettes (Echarri et al., 2019; Golani et al., 2019). The wide array of structures and actions of caveolae across many different tissues and pathways highlights this small organelle's diverse role in signaling and physiology. Yet, much remains to be uncovered about their regulation, function, and mode of action. 
The caveolar coat is minimally composed of several proteins important for forming and stabilizing the bulb-shaped membrane invagination. The key proteins are Caveolin (three orthologous in human, Cav1-3), Cavins (Cavin1-4), the BAR protein domain-containing syndapin/Pacsin2, and the dynaminrelated ATPase EHD2 (see Figure 1, previously reviewed in the literature; Han et al., 2016b; Lamaze et al., 2017; Parton et al., 2020c). In vitro and in vivo studies have shown that Caveolin/cholesterol complexes incorporate into the plasma membrane forming elongated and rather shallow invaginations (Fernandez et al., 2002; Hayer et al., 2010a; Ariotti et al., 2015; Han et al., 2020). Caveolin complexes alone do not form the typical bulb shape. Therefore, Cavin coat proteins have been proposed to be essential for generating the classic "cave-like" invaginations. Specifically, Cavins are recruited from the cytosol, oligomerize into trimers, and surround the caveolar membrane resulting in a structured caveolar coat as illustrated in Figure 1A (Gambin et al., 2014; Kovtun et al., 2015; Ludwig et al., 2016; Stoeber et al., 2016). Furthermore, it has been shown that Pacsin2 is important for bending the membrane and stabilizing caveolar invaginations at the plasma membrane (Hansen et al., 2011; Senju et al., 2011, 2015; Seemann et al., 2017). A similar function was found for the ATPase EHD2. EHD2 specifically localizes to the neck of caveolae (Morén et al., 2012; Stoeber et al., 2012; Ludwig et al., 2013). Recently, the EHD2 binding partner (EHBP1) was identified as another stabilizer of caveolae in endothelial cells (Webb et al., 2020). Finally, a BAR protein, FBP17, was discovered to be important for the formation of caveolae rosettes at the plasma membrane (Echarri et al., 2019).

Despite the large number of caveolae in muscle and endothelial cells or adipocytes, the loss of caveolae due to Cav1 or Cavin1 deletion is not generally lethal (overview of knockout models reviewed in Le Lay and Kurzchalia, 2005; Hansen et al., 2013; Cheng and Nichols, 2016). However, investigations of various Caveolin or Cavin deficient mouse models has indicated impaired lipid metabolism and lipodystrophy, cardiomyopathies, blood pressure changes, and muscular dystrophy in these animals (Pilch and Liu, 2011; Cheng and Nichols, 2016). It should be noted that some of these phenotypes could be due to noncaveolar functions of Cav1 as recently reviewed (Pol et al., 2020). Additionally, altered Cav1 and Cavin1 expression, mutations in human Caveolin genes, as well as modified caveolae endocytosis and trafficking can be linked to metabolic diseases including obesity and lipodystrophy (Catalán et al., 2008; Kim et al., 2008; Pilch and Liu, 2011; Schrauwen et al., 2015; Matthaeus et al., 2020), cancer (Lee et al., 2002; Martinez-Outschoorn et al., 2015; Ketteler and Klein, 2018) as well as cardiovascular diseases (Cohen et al., 2004a; Han et al., 2016a; Lian et al., 2019) or myopathies (Gazzerro et al., 2010; Dewulf et al., 2019). Therefore, caveolae are currently under investigation as novel therapeutic targets for disease (Carver and Schnitzer, 2003; Navarro et al., 2014).

The process of intracellular membrane traffic, including caveolae endocytosis, transcytosis, transport, and targeting, requires specific signals and regulatory modules to direct movement inside the cell. Nucleoside triphosphates Adenosine5'-triphosphate (ATP) and Guanosine-5'-triphosphate (GTP) serve as cellular energy resources to drive, localize, and direct these actions. Both nucleosides play essential roles during intracellular trafficking to promote membrane interactions and deformations, protein-protein interactions, and conformational changes in molecular machines. Here, we summarize the state of understanding of caveolae membrane trafficking and highlight the roles of ATP and GTP-dependent processes within these specialized membrane structures.

\section{CAVEOLAE TRAFFICKING}

How do caveolae move? Caveolae endocytosis and trafficking has been observed in many cell types although the cellular consequences of these movements are currently not wellunderstood. The role and even occurrence of caveolae traffic has, indeed, been controversial (Parton and Howes, 2010; Cheng and Nichols, 2016; Parton et al., 2020a). Several studies have shown, however, that caveolae endocytosis supports viral entry and receptor internalization, and caveolae membrane trafficking has been linked to cellular lipid homeostasis and movement. Here, we divide caveolar internalization into 5 steps: (1) caveolae dynamics at the plasma membrane, (2) detachment from the cell membrane, (3) fusion with endosomes followed by accumulation in lysosomes or (4) non-endosomal trafficking to intracellular organelles, and finally (5) recycling of caveolae (see overview in Figure 2 and the following sections).

With these steps in mind, caveolae internalization and traffic, however, must be distinguished from caveolae flattening and disassembly. Several studies have indicated that increased membrane tension due to osmotic shock and membrane stretch could lead to caveolar membrane flattening. Here, caveolae proteins such as Cavins or EHD2 are proposed to be released into the cytosol and are able to move independently of caveolar membranes (Sinha et al., 2011; Cheng et al., 2015; Garcia et al., 2017; Lim et al., 2017; Torrino et al., 2018). However, this mechano-adaptive caveolae behavior is cargo-independent and therefore different from classical endocytosis and traffic (Del Pozo et al., 2021). Recently, it was shown that cellular stress induced by UV light could also trigger the disassembly of caveolae and the release of caveolar proteins into the cytosol (McMahon et al., 2019). Previous studies further showed that caveolae serve as cellular membrane tension sensors that are coupled to mechano-transduction pathways such as the Hippo system involving the transcriptional regulators YAP and TAZ (Echarri and Del Pozo, 2015; Dewulf et al., 2019; Del Pozo et al., 2021). Here, caveolae are able to sense changes in plasma membrane tension and induce transcriptional changes as well as provide membrane reservoirs to protect the cell from mechanical stress. These behaviors of caveolae are distinct from the classic traffic routes we will focus on in this review.

The study of caveolae trafficking has been complicated by many technical difficulties. To investigate caveolae dependent endocytosis, cholera toxin and simian virus 40 have been the standard cargo. Yet, detailed analysis has shown that both cargos are not exclusively internalized by caveolae. This has led to some amount of conflicting data (Nichols, 2002; Cheng and Nichols, 


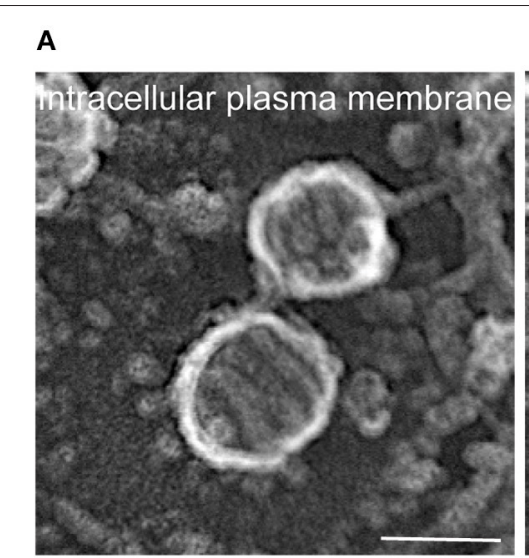

C

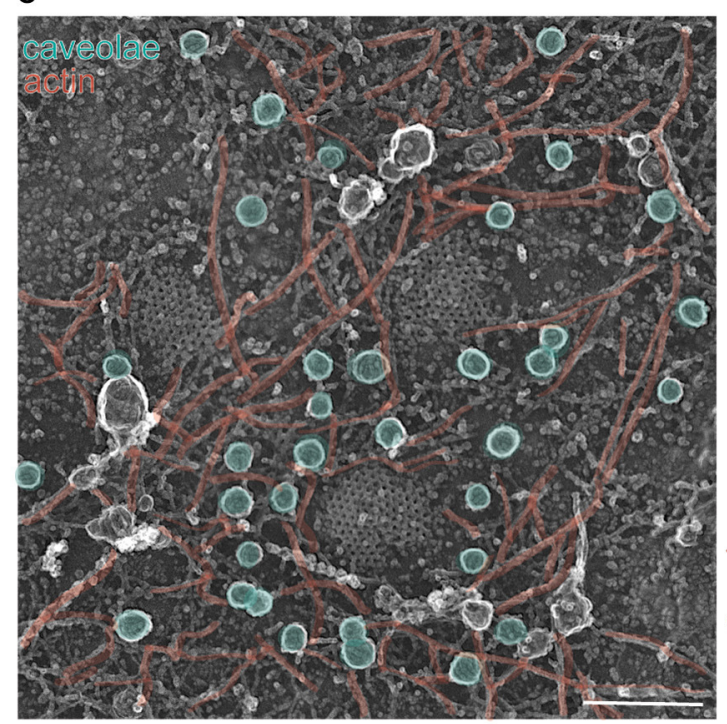

B
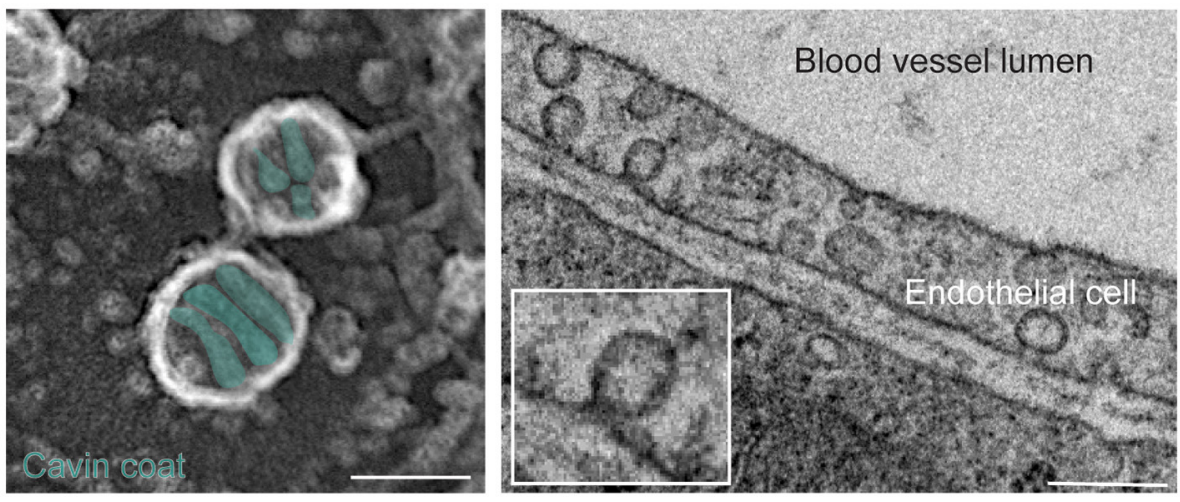

D

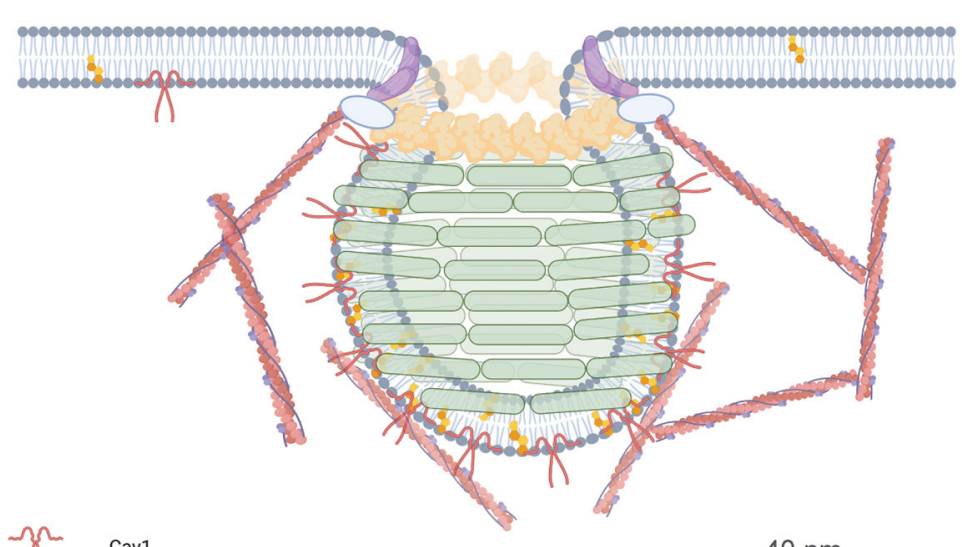

$\underbrace{Z^{2}}_{\text {EHD2 }}$

av1

$40 \mathrm{~nm}$

FIGURE 1 | Caveolae structure and components. (A) Caveolae imaged in unroofed mouse embryonic fibroblasts (MEF) by platinum replica EM. The typically caveolae coat generated by Cavin protein complexes (colored in green) surround the Cav1 induced plasma membrane invaginations. Scale bar $120 \mathrm{~nm}$. (B) 2D TEM image of caveolae in endothelial cells of blood vessels in mouse heart sections. Scale bar $200 \mathrm{~nm}$. (C) The MEF plasma membrane contains randomly distributed caveolae (in green) embedded with actin filaments (red). Scale bar $250 \mathrm{~nm}$. (D) Schematic overview of caveolae and its components.

2016). To date, no caveolae-specific cargo has been identified (Parton et al., 2020a). This makes it challenging to specifically monitor intracellular caveolae trafficking. Furthermore, noncaveolar Cav and Cavin localization, and overexpression effects of Cav/Cavin proteins, makes it difficult to distinguish between intracellular Cav/Cavin protein migration and caveolae endocytosis (summarized for Cav1 in Pol et al., 2020, noncaveolar Cavin function see Jansa et al., 1998; Liu and Pilch, 2016; McMahon et al., 2019). Additionally, the comparison of Cav1 overexpressing cells with genome-edited Cav1 cells revealed that only a portion of caveolae are actually motile and the majority stay immobile at the plasma membrane (Shvets et al., 2015). In contrast, overexpressed GFP-tagged Cav1 results in many highly mobile Cav1 molecules in cells which may not be assigned to caveolae migration. Therefore, caveolae endocytosis studies should be evaluated with care. Specifically, untangling the movement of coated caveolae membrane-containing vesicles from packets of caveolae proteins without membrane is a challenge. The following section will summarize current caveolae trafficking concepts while highlighting the distinct steps of the process.

\section{Caveolae Detachment From the Plasma Membrane}

Caveolae are highly dynamic membrane domains, that are capable of moving laterally in the plasma membrane, similar to lipid rafts (Pelkmans and Zerial, 2005; Boucrot et al., 2011; Shvets et al., 2015). However, it was shown in vitro and in vivo that EHD2 localizes to caveolar necks. In particular, the observation of an increased number of static caveolae in cells overexpressing EHD2 led to the hypothesis that EHD2 stabilizes caveolae at the plasma membrane (Morén et al., 2012; Stoeber et al., 2012; Ludwig et al., 2013; Matthaeus et al., 2020). Besides EHD2, Pacsin2 is also involved in caveolae plasma 

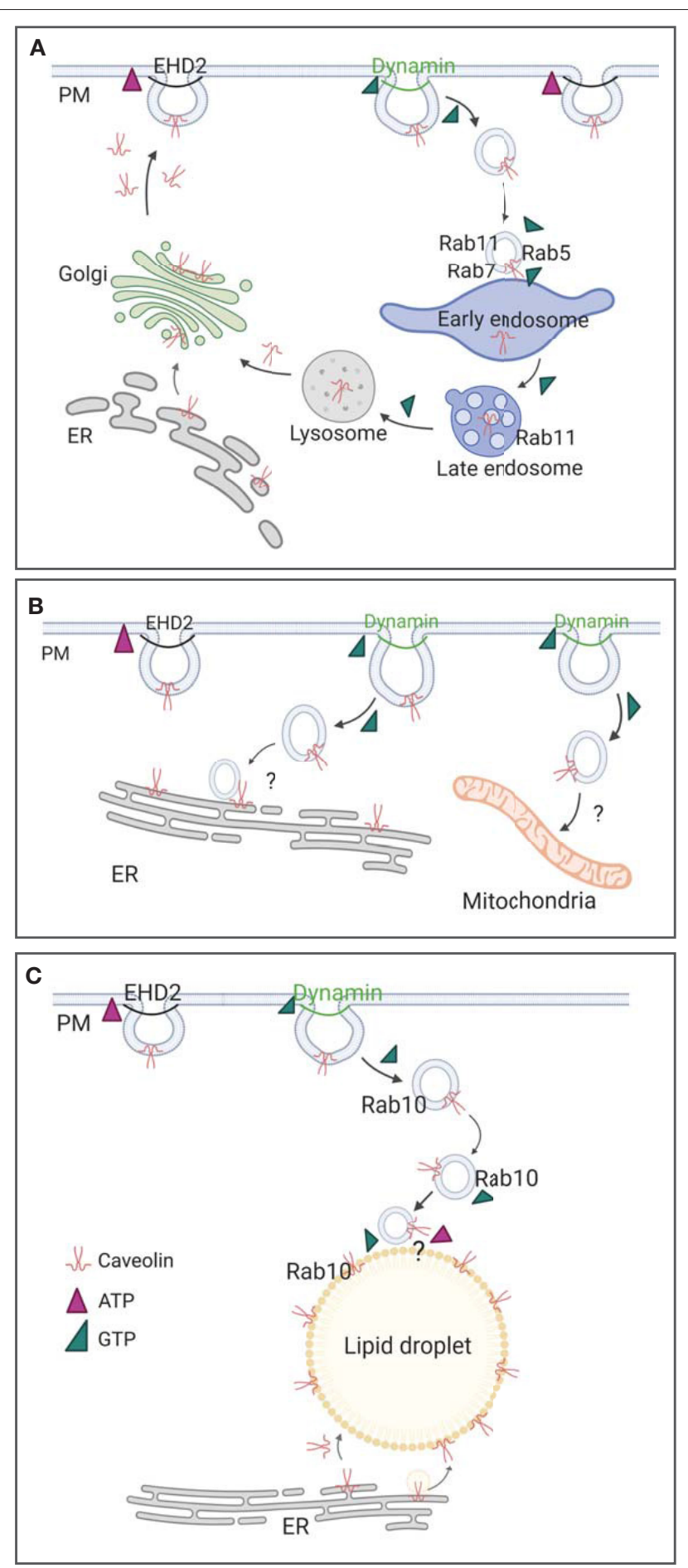

FIGURE 2 | Caveolae endocytosis and trafficking. (A) Classic caveolae endocytosis from the plasma membrane to early and late endosomes, followed to lysosomes, occurs in various cell types. Rab5, 7, and 11 are assigned to caveolae trafficking, ATP (pink triangle) and GTP (green triangle) dependent processes are illustrated. (B) Caveolae trafficking to endoplasmic reticulum (ER) and mitochondria is suggested based on initial proteomics data and detailed EM images. (C) Caveolae trafficking from the plasma membrane to lipid droplets can be observed in adipocytes and fibroblasts. PM, plasma membrane; Dyn, Dynamin; ER, endoplasmic reticulum; question mark indicates unknown processes and proteins. membrane stabilization (Senju et al., 2011, 2015). Deletion of either EHD2 or Pacsin2 results in increased caveolae mobility and internalization. Most likely, EHD2 removal from caveolar neck promotes caveolae detachment from the plasma membrane followed by intracellular trafficking. How exactly detachment occurs is currently unknown. Dynamin has been proposed to be important for this process (Henley et al., 1998; Oh et al., 1998, 2012). Yet, clear evidence that dynamin acts alone or in combination with other proteins, such as intersectin (Predescu et al., 2003, 2012), is lacking. It is also possible that the fission of caveolae from the plasma membrane is driven by other proteins. Indeed, this is common for dynamin independent endocytosis (e.g., CLICs, Mayor et al., 2014; Sathe et al., 2018) and ESCRT III complex protein driven invaginations (Hanson et al., 2008; Rossman and Lamb, 2013).

To study caveolae scission and trafficking, one needs to differentiate vesicles from membrane bound caveolae. In the past this has been difficult for various endocytic pathways due to their small size and fast dynamics. In fixed cells, however, caveolar vesicles can be distinguished by EM or electron tomography as vesicles containing an enclosed lipid bilayer (Popescu et al., 2006; Hubert et al., 2020b; Matthaeus et al., 2020; Webb et al., 2020). Novel super resolution imaging techniques such as Stochastic Optical Reconstruction microscopy (STORM) and Stimulated Emission Depletion (STED) microscopy with resolution limits up to $40 \mathrm{~nm}$ are also able to identify caveolar vesicles (Platonova et al., 2015; Tachikawa et al., 2017; Yeow et al., 2017; Khater et al., 2018; Matthaeus et al., 2019). Of special interest with regard to caveolar vesicle trafficking is the application of STED and structured-illumination microscopy (SIM) to live cells allowing single caveolae to be tracked throughout the cell. Currently, caveolae trafficking is mainly studied with total internal reflection fluorescence (TIRF) microscopy. However, TIRF is diffraction limited in the plane of the cover glass and in the axial plane limited to signals within $\sim 200 \mathrm{~nm}$ of the plasma membrane. Therefore, deeper caveolae events cannot be seen. In summary, rapidly developing imaging techniques will help to further elucidate the exact caveolar detachment process at the plasma membrane and allow single organelles to be monitored as they move through the cytosol. These studies will finally reveal how caveolae move, where they go, and what pathways they participate in within living cells and tissues.

\section{Intracellular Caveolae Trafficking}

After detachment from the plasma membrane, caveolae can be internalized and traffic to intracellular organelles. Which signaling events, cargos, or ligands induce caveolae internalization are, however, unclear and has led to some controversy in the field. Thus, the exact role for caveolae traffic has been difficult to generalize. This is in contrast to clathrin mediated endocytosis where defined cargos and trafficking routes are well-established and mainly accepted. Recent data has suggested that high levels of extracellular cholesterol and glycosphingolipids are able to stimulate caveolar dynamics (Hubert et al., 2020b). Also, albumin (Minshall et al., 2000; Botos et al., 2008), okadaic acid and glycosphingolipids (Parton et al., 1994; Shvets et al., 2015), cholesterol and long-chain fatty acids 
(Le Lay et al., 2006; Hao et al., 2020), simian virus 40 (Tagawa et al., 2005), and endothelin (Oh et al., 2012) are thought to be potential detachment and internalization triggers in some cell types. Taken together, various tissue and cell specific signaling events or ligands may trigger caveolae internalization. The resulting intracellular caveolae trafficking routes include the conventional endocytic pathway, as well as caveolae migration to the endoplasmic reticulum and lipid droplets (see overview in Figure 2, and detailed description below). Likewise, studies have shown that caveolae detachment and return of caveolae vesicles to the plasma membrane can occur (Pelkmans and Zerial, 2005; Hubert et al., 2020a).

\section{Endocytic Caveolae Pathway}

When caveolae bud off from the plasma membrane they can fuse with the early endosome. This is followed by maturation of these organelles into late endosomes, multivesicular bodies, and finally degradation of their contents within lysosomes (Hayer et al., 2010b; Shvets et al., 2015). Previous studies showed that Cav1 co-localizes with early and late endosomal markers including Rab5 and Rab7, followed by accumulation into the lysosomes (Pelkmans et al., 2004; Botos et al., 2008; Hayer et al., 2010b; Shvets et al., 2015). Notably, Shvets et al. (2015) determined that caveolae mediated endocytosis in 3T3 fibroblasts comprises a minor fraction of total cellular endocytosis (ca. 5-10\% of total endocytic vesicles). By using Cav1 immunogold labeling, Botos et al. (2008) observed an accumulation of Cav1 in multivesicular bodies after detachment from the plasma membrane. Furthermore, polarized epithelial cells contain Cav1 endocytosis and co-localization with the specific apical recycling marker Rab1la (Lapierre et al., 2012). In line with these observations, several proteomics and biochemistry studies showed an enrichment of small Rab GTPases, SNAP molecules, and the vesicle SNARE protein VAMP2 in isolated caveolae fractions (Schnitzer et al., 1995; Aboulaich et al., 2004; McMahon et al., 2006; Wypijewski et al., 2015). These are necessary for a functional membrane fusion machinery needed for the endocytic pathway. In summary, these data illustrate that caveolae are endocytosed. Most likely, viruses such as the simian virus 40 use this caveolar endocytic path way to enter and infect cells (Pelkmans et al., 2001; Tagawa et al., 2005). Furthermore, receptor internalization may be regulated by this pathway, e.g., TGF-beta type 1 (He et al., 2015) or insulin receptor (Fagerholm et al., 2009), although distinct caveolar specific receptors have not been observed.

\section{Caveolae Trafficking to Endoplasmic Reticulum and Mitochondria}

Recent advances in imaging and proteomics have uncovered novel caveolae trafficking routes outside the classic endocytic pathway. First, based on the observation of caveolae dependent cholera toxin and autocrine motility factor accumulation in the endoplasmic reticulum (ER) and Golgi, it was suggested that caveolae are able to migrate from the cell surface to the ER (Pelkmans et al., 2001, 2004; Le and Nabi, 2003). Additionally, proteomics of isolated caveolar membrane domains showed an increased amount of ER related proteins (McMahon et al., 2006).
Recently, it was shown that Cav1 impairs the formation of ERmitochondria contact sites and is involved in Drp1 mediated mitochondria fusion (Bravo-Sagua et al., 2019). However, clear evidence of Cav1 and/or caveolae originating from the plasma membrane under these circumstances is lacking. Indeed, the work of Bravo-Sagua et al. (2019) indicates a specific ER related function of Cav1 independent of caveolae endocytosis.

Caveolae have been proposed to form specific ER membrane contact sites. A detailed high resolution EM analysis of rat smooth muscle cells indicated that the majority of caveolae (either located at the plasma membrane or detached) are close to the sarcoplasmic reticulum (SR) (Popescu et al., 2006). The authors further detected electron densities in the caveolae membrane reaching to the corresponding SR membrane and containing potential tethers that establish membrane contact sites. The same observation was found for mitochondria, although caveolae-mitochondria contact sites are less abundant (Popescu et al., 2006). Currently it is not known if caveolae migrate from the plasma membrane to mitochondria. However, previous studies showed that Cav1 is also found in mitochondria (Li et al., 2001; Fridolfsson et al., 2012; Foster et al., 2020).

\section{Caveolae Trafficking to Lipid Droplets}

Caveolae trafficking to lipid droplets is of particular interest for lipid homeostasis and metabolism. Initially, Cav1 and independently Cav2, were found at lipid droplets. It was suggested that Cav1 or Cav2 originated from the ER and migrates to lipid droplets because pharmacological inhibition of ER vesicle transport was seen to block Cav translocation (Fujimoto et al., 2001; Ostermeyer et al., 2001; Pol et al., 2001, 2004). By overexpressing a Cav1 mutant leading to ER accumulation, Cav1 re-locates to the lipid droplet coat, most likely during lipid droplet formation (Ostermeyer et al., 2004; Pol et al., 2004). The lipid droplet coat consists, in contrast to other membranebound organelles, of a phospholipid monolayer, resulting in a unique set of proteins targeted to this area (Walther and Farese, 2009; Kory and Walther, 2016). The recruitment and localization of proteins directly from the cytosol to the lipid droplet coat requires amphipathic helices to ensure correct localization (Kory and Walther, 2016). Caveolins contain amphipathic lipid binding domains and therefore are likely able to bind to lipid droplets (Ariotti et al., 2015; Root et al., 2019).

Cav1 trafficking from the plasma membrane to lipid droplets was first described in 3T3-L1 adipocytes using immunostaining, EM, and biochemistry (Le Lay et al., 2006; Blouin et al., 2010). Blouin et al. (2010) further detected Cavin1, EHD2 and semicarbazide-sensitive amine oxidase (SSAO, localizes within the adipocyte caveolae domain, Souto et al., 2003) at the lipid droplet coat indicating that not Cav1 alone but caveolae are recruited to lipid droplets. Interestingly, Cav1 (most likely Cav2 as well) is recruited to a specific lipid droplet subpopulation (Storey et al., 2011). The isolation and purification of lipid droplets revealed a Cav1 positive lipid droplet fraction that is also enriched in Perilipin1, a protein protecting stored lipids within the droplets against lipolysis (Sztalryd and Brasaemle, 2017). In contrast, Cav1 negative droplets showed an accumulation of ADRP (adipocyte differentiation-related protein, Storey et al., 2011). Furthermore, 
Cav1 and Perilipin1 are able to form a complex, indicating that Cav1 is involved in the regulation of lipolysis of the lipids stored in the lipid droplets (Cohen et al., 2004b; Storey et al., 2011).

These data suggest that there is direct trafficking from the plasma membrane. However, how this is carried out and if Cavl alone or caveolae vesicles are transferred is currently not understood in mechanistic detail. Recent data from Matthaeus et al. (2020) further supported this idea as increased caveolae mobility and endocytosis resulted in increased lipid droplet size and increased fatty acid uptake. Additionally, lipid accumulation within caveolar membrane domains increased caveolae detachment (Shvets et al., 2015; Hubert et al., 2020b) indicating the importance of this process. Based on these data, we propose the following model. Caveolae may serve as lipid sensors that accumulate specific lipids such as cholesterol, sphingolipids, and fatty acids. By reaching a critical amount of lipids, the stability of membrane-attached caveolae decreases and caveolae detach. This sensing is followed by caveolae traffic to lipid droplets. However, it is currently unclear how caveolae sense the accumulation of lipids within their membrane domains, how EHD2 disassembles, and how this scission is regulated. It is also unclear if caveolae migrate as vesicles to the lipid droplet coat and form membrane contact sites (such as shown for other organelles, reviewed by Olzmann and Carvalho, 2019; Thiam and Dugail, 2019; Henne, 2020), or if Cav1 alone is able to reach them.

Taken together, there is much data illustrating caveolae internalization from the plasma membrane followed by intracellular trafficking. Currently, the conventional pathway is the best studied. Yet, proteomic approaches suggest caveolae target to other organelles and these must be evaluated in detail. Super resolution imaging techniques can help to track the global movements of caveolae throughout cells. Besides the different intracellular caveolae trafficking pathways, the initial steps, ATP dependent EHD2 stabilization at the plasma membrane, and the GTP dependent dynamin-based scission of the caveolar bulbs, are all essential for caveolae internalization. Next, we discuss the function and importance of the energy-dependent enzymes including EHD2 and dynamin in these specific processes.

\section{ATP DEPENDENT EHD2 OLIGOMERIZATION AT THE CAVEOLAR NECK}

How is EHD2 oligomerization and its effect on caveolae plasma membrane stabilization and detachment regulated? Recent structural, cellular, and physiological data indicated that the ATP-dependent oligomerization of EHD2 is an important regulator for caveolae traffic. Eps15 homologous domain containing protein 2 (EHD2) and its related EHD proteins belong to the dynamin protein family as they share the same overall domain organization (Daumke et al., 2007). In mammals, four EHD orthologs are found (EHD1-4) that show distinct tissue-specific expression, localization, and functions (Pohl et al., 2000; George et al., 2007). EHD1, 3 and 4 are observed at early and late endosomes and EHD2 is located primarily at the caveolar neck (reviewed in
Naslavsky and Caplan, 2011; Bhattacharyya and Pucadyil, 2020). All EHD proteins are able to bind to and bend phospholipid membranes (Daumke et al., 2007; Melo et al., 2017; Deo et al., 2018).

Structurally, EHD proteins share sequence similarity of up to $82 \%$ (Pohl et al., 2000) supporting the idea that EHDs could share a common function and lipid binding mechanism. EHD1-4 contain a stalk or helical region that is involved in membrane binding, a G-domain comprising the ATPase and oligomerization domain, and the specific EH domain, a Eps15 homologous protein sequence (Figure 3A, Daumke et al., 2007; Shah et al., 2014). EHD proteins are dimers which can be activated after membrane recruitment followed by ATP binding (Daumke et al., 2007; Hoernke et al., 2017; Melo et al., 2017). Mechanistically, the opening of the EHD dimer by repositioning of the $\mathrm{EH}$ domains results in the rearrangement of the stalk, freeing it to bind to the lipid bilayer. Detailed studies using EHD2 mutants in liposome binding assays accompanied with in vivo analysis showed that residues F322 and K327 are essential for correct membrane binding (Stoeber et al., 2012; Shah et al., 2014). ATP binding induces the oligomerization of EHD proteins resulting in liposome tubes that are decorated with EHD ring-like oligomers (Daumke et al., 2007; Melo et al., 2017). The diameter of these EHD tubes ranges between 20 and $80 \mathrm{~nm}$ indicating that EHD2 could form a ring surrounding the caveolar bud neck (Figure 3C). Ludwig et al. (2013) clearly localized EHD2 by immunogold labeling in EM section to the caveolar neck (Morén et al., 2012; Ludwig et al., 2013). In support of this, high resolution EM images show a distinct ring-like electron density at the caveolar neck (Popescu et al., 2006; Richter et al., 2008). A correlative imaging approach would be important to show that this density is indeed EHD2.

Upon ATP hydrolysis, the EHD oligomer disassembles and relocates from the caveolae membrane to the cytosol. Importantly, the ATP-dependent oligomerization step of EHD2 is key to stabilizing EHD2 at caveolae. Specifically, EHD2 mutants without the ATPase domain fail to oligomerize, and therefore fail to stabilize caveolae at the plasma membrane (Morén et al., 2012; Stoeber et al., 2012; Matthaeus et al., 2020). Furthermore, it was shown that in 3T3 fibroblasts EHD2 loss can be rescued by other EHD proteins (Yeow et al., 2017). However, a global EHD2 knockout mouse did not exhibit the same observations in adipocytes, fibroblasts, or endothelial cells (Matthaeus et al., 2019, 2020).

This raises the important question, why is EHD2, and in particular the ATP-dependent oligomerization of EHD2, essential for correct caveolae function and behavior? Several cellular studies have shown an increased caveolae mobility, endocytosis, and removal from the plasma membrane when the EHD2 gene is deleted or its ATP function impaired (Morén et al., 2012; Stoeber et al., 2012; Hoernke et al., 2017; Yeow et al., 2017). Endocytosis of transferrin receptor was not impaired in EHD2 knockout or EHD2 overexpressing cells (Pekar et al., 2012), highlighting the specific role of EHD2 in regulating caveolae dependent endocytosis. Additionally, overexpression of EHD2 mutants lacking their lipid binding or ATPase function also resulted in increased caveolae dynamics as a result of decreased 
A EHD2 dimer, AMPPNP bound

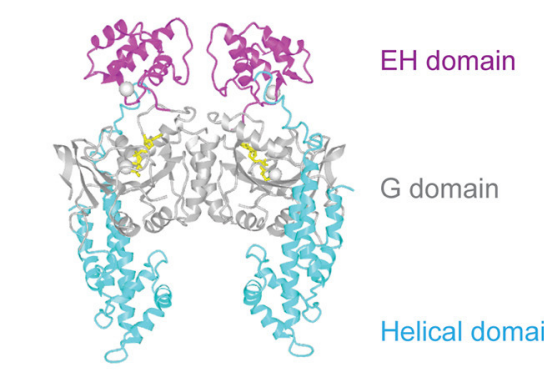

B Dynamin dimer, nucleotide free

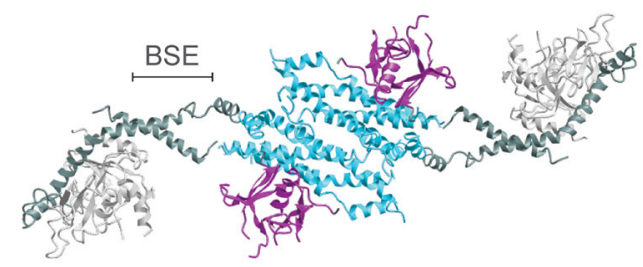

G domain $\quad \mathrm{PH}$ domain Stalk domain
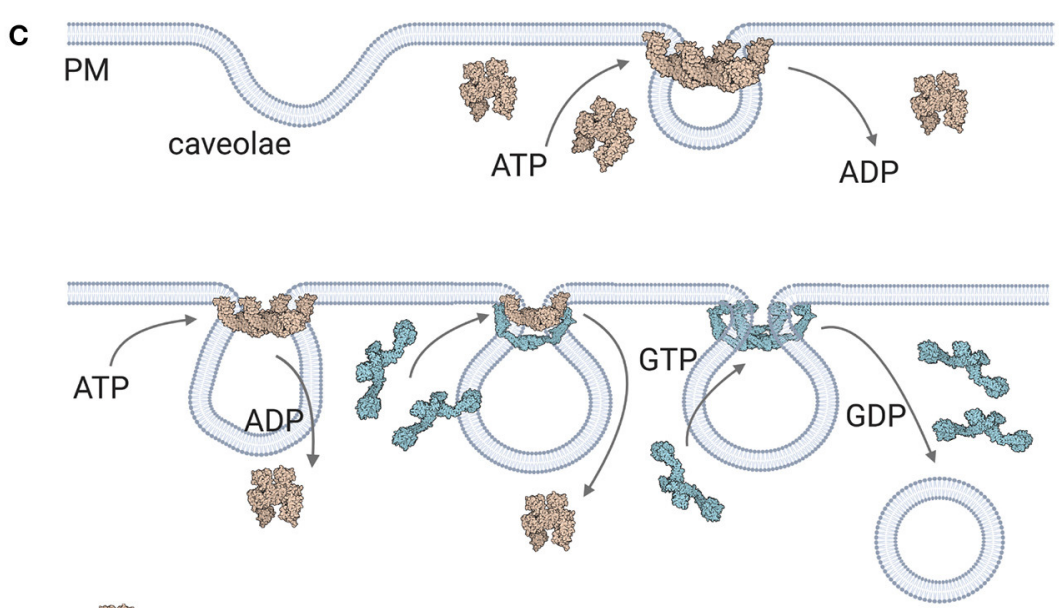

EHD2

caveolar vesicle

Dynamin

FIGURE 3 | EHD2 and dynamin at the caveolar neck. (A) Crystal structure of EHD2 dimer bound with non-hydrolyzing AMPPNP (PDB 2QPT, Daumke et al., 2007). (B) Crystal structure of nucleotide free dynamin dimer (PDB 3SNH, Faelber et al., 2011). (C) ATP and GTP dependent caveolae stabilization and detachment. After caveolae formation, EHD2 oligomerizes in an ATP dependent manner in large rings at the neck of caveolae. Disassembly of EHD2 oligomers occurs after ATP hydrolyzation, followed by dynamin recruitment to the caveolar neck and GTP dependent membrane scission. Membrane binding of EHD2 and dynamin results in confirmational change in both proteins (membrane bound EHD2 PDB 5MTV, Melo et al., 2017; membrane bound, constricted dynamin PDB 6DLU, Kong et al., 2018).

caveolar membrane stabilization (Stoeber et al., 2012). In the last few years, two cell based studies showed an involvement of EHD2 in lipid accumulation (Li et al., 2016; Morén et al., 2019). Li et al. (2016) revealed an increased lipid droplet size in hepatocytes lacking EHD2. The authors proposed that EHD2 together with Rab10 and Ehbp1 is involved in lipolysis. Contrary, Moren et al. (2019) observed that EHD2 silencing in 3T3-L1 derived adipocytes reduced lipid droplet sizes. Additionally, Yeow et al. (2017) and Torrino et al. (2018) observed increased vulnerability to changes in membrane tension in EHD2 lacking fibroblasts or HeLa cells.

The generation of an EHD2 knockout mouse model helped to determine EHD2's caveolae function in vivo. We observed in mice that globally lacked EHD2 increased lipid droplet sizes in various tissue types although the total number of lipid droplets decreased (Matthaeus et al., 2020). Additionally, an increase in fatty acid uptake was detected in EHD2 knockout adipocytes and mouse embryonic fibroblasts. Detailed electron microscopy and tomography further supported the idea that EHD2 is essential for correct membrane stabilization of caveolae as EHD2-lacking tissues contained large numbers of detached caveolae (Matthaeus et al., 2019, 2020; Fan et al., 2020; Webb et al., 2020). Additionally, we observed an increased detachment of caveolae due to EHD2 removal resulting in reduced calcium entry and a resultant lack of activated eNOS and NO generation in endothelial cells. This lead to reduced blood vessel relaxation in EHD2 knockout mice and reduced running wheel endurance (Matthaeus et al., 2019). Taken together, these in vivo data clearly indicate that EHD2 oligomerization at the caveolar neck is an essential cell function with severe physiological consequences when EHD2 is missing or its ATPase function is impaired.

\section{GTP DEPENDENT DYNAMIN FACILITATED MEMBRANE SCISSION OF CAVEOLAE}

Caveolae detachment has been ascribed to dynamin catalyzed membrane scission. This raises the question of how dynamin drives fission of caveolae and how it is regulated. Dynamin is 
a well-known lipid binding GTPase that bends membranes and catalyzes fission. Structurally, it contains the N-terminal GTPase domain ( $\mathrm{G}$ domain), followed by the central bundle signaling element (BSE), the stalk region, and the pleckstrin homology (PH) domain at the C-terminus (Figure 3B, Faelber et al., 2011). The stalk domain mediates dimerization, larger oligomers further include binding between BSE. Dynamin, with its 3 orthologs in mammalians, is expressed in all cell types from early embryonic time points on and is essential in clathrin mediated endocytosis (Ferguson and De Camilli, 2012). In particular, Dyn1 is found in the brain in high levels, Dyn3 in muscle, testis, brain and lung, and Dyn2 is a ubiquitous isoform expressed in many cell types. In clathrin mediated endocytosis, dynamin regulates the scission of clathrin coated membrane pits from the plasma membrane after coat assembly and elongation of the neck. However, dynamin and its related proteins such as interferon-inducible myxovirus resistance $(\mathrm{Mx})$, Optic atrophy type 1 (Opa1) or Dynamin1 like protein (Dnm1l) are involved in various other cellular processes within different organelles such as mitochondria fusion (Ferguson and De Camilli, 2012; Daumke and Praefcke, 2016).

How does dynamin facilitate membrane scission at caveolae? The scission of a phospholipid membrane requires the transition of the chemical energy gained during GTP hydrolysis into mechanical constriction to merge the lipid bilayers of the vesicle neck (Daumke and Praefcke, 2016). It is proposed that the hydrolysis of a few GTP molecules can provide the necessary energy for scission (Morlot et al., 2012). Structurally, the stalk region of dynamin forms ring-like oligomers surrounding the membrane (Kong et al., 2018). Following GTP binding, the GTPase domains dimerize, and GTP hydrolysis occurs resulting in a conformational change within the dynamin oligomer. This "power-stroke" is thought to pull the adjacent dynamin filaments along each other and thereby constricting the underlying membrane (Antonny et al., 2016; Daumke and Praefcke, 2016). Indeed, several in vivo studies showed the GTP dependent dynamin oligomerization and membrane scission at clathrin coated pits (Takei et al., 1995; Iversen et al., 2003; Grassart et al., 2014). Based on these results, it was concluded that caveolae detachment from the plasma membrane is also driven by dynamin. First, Schnitzer et al. (1996) showed a GTP dependent caveolae scission in a cell free assay indicating the involvement of a GTP handling enzyme (Schnitzer et al., 1996). Independently, Oh et al. (1998) and Henley et al. (1998) then described the GTP dependent caveolae internalization is mediated by dynamin (Henley et al., 1998; Oh et al., 1998). Furthermore, the involvement of dynamin was also observed in caveolae dependent albumin transcytosis (Shajahan et al., 2004). Importantly, overexpression of the non-GTP hydrolyzing dynamin mutant (Dyn2-K44A) abolished caveolae mobility, detachment, and trafficking from the plasma membrane in several cell types (Pelkmans et al., 2001; Senju et al., 2011; Oh et al., 2012). Taken together, these data indicated the involvement of dynamin in caveolae scission and detachment.

Some previous studies struggled to clearly localize dynamin to caveolar invaginations in different cell types. Using EM immunogold labeling, however, Dyn2 localization in caveolae was shown in kidney cells (Yao et al., 2005), and Dyn2 overexpressing MEFs or endothelial cells also showed co-localization with Cav1 (Shajahan et al., 2004; Matthaeus et al., 2020). The general difficulty of localizing dynamin could be caused by the fact that dynamin might only assembles at the caveolar neck shortly before internalization, followed by a fast re-location into the cytosol. To overcome this issue, the accumulation of non-hydrolyzing dynamin mutants at the caveolar neck was used to visualize dynamin with STORM microscopy (Platonova et al., 2015). Yao et al. (2005) could further identify a specific binding interaction between Cav1 and Dyn2. The exact role of dynamin at caveola is, however, still unclear.

Importantly, oligomerization of dynamin at the plasma membrane can only occur when thin membrane tubes are present. As previously described, EHD2 oligomerizes in rings around lipid bilayers in diameters ranging from 20 to $80 \mathrm{~nm}$. Therefore, at the caveolar neck, we propose that EHD2 is key to create the necessary membrane structure for correct dynamin assembly and subsequent fission of caveolar invaginations (see model in Figure 3C). It was proposed previously, that EHD proteins are able to recruit dynamin to membrane tubes (Jakobsson et al., 2011), indicating an interaction between these two enzymes. However, based on the steric hindrance at the caveolar neck due to the large EHD2 oligomer, we suggest that before dynamin locates to the caveolae, EHD2 must start to disassemble (after ATP hydrolyzation) and relocate to the cytosol. Then, dynamin would be recruited to caveolae, followed by its oligomerization around the caveolar neck. The GTP dependent power stroke of dynamin would result in membrane scission. Later, detached caveolae would migrate to other intracellular organelles and dynamin would relocate to the cytosol. Further experiments, especially live cell high resolution imaging, are needed to test the temporal sequence of these events. Taken together, recent data shows the importance of GTP-dependent dynamin regulation during caveolae detachment. However, how these spatial and temporal mechanisms operate at the caveolar neck is still unknown and requires further study. Cleary, the interplay of EHD2 and dynamin at the membrane neck of caveolae is of particular interest for future work.

\section{OTHER REGULATORS FOR CAVEOLAE TRAFFICKING}

\section{Rab GTPases in Caveolae Internalization and Trafficking}

Besides dynamin and EHD2, several other GTP/ATP dependent proteins were assigned roles in caveolae trafficking. Specifically, Rab proteins have been linked with caveolae endocytosis. Rab proteins are small Ras-like GTPases that switch between the "on," GTP bound-and the "off"-GDP bound-state and therefore temporally and spatially regulate the recruitment of various effector proteins such as vesicle coat proteins, membrane fusion complexes or motor proteins (see review Stenmark, 2009). The relatively high cytosolic GTP concentration ( $\sim 0.5 \mathrm{mM}$; Traut, 1994) allows a very fast exchange of GDP 
with GTP securing the fast switching between the "off" and "on" state. It can be ventured that local changes in the GTP concentration might influence the activation of certain Rab molecules and their binding affinity to corresponding effector proteins. As Rab molecules are essential vesicle trafficking regulators it was expected to detect Rabs also at caveolar vesicles. Indeed, several studies focusing on caveolae endocytosis revealed that caveolae trafficking depends on Rab5, Rab7, and Rab11 (Pelkmans et al., 2004; Botos et al., 2008; Hayer et al., 2010b; Shvets et al., 2015). There, the Rab proteins direct the traffic of caveolae vesicles to early and late endosome and lysosome. However, to date, no caveolar specific Rab molecules were found which makes it challenging to study. Novel techniques analyzing protein-protein interaction such as SplitAPEX2 (Han et al., 2019) or fluorescence resonance energy transfer (FRET) could help to detect caveolae specific $\mathrm{Rab}$ molecules within distinct trafficking routes or organelles. Additionally, caveolae specific Rabs would help to determine the cellular implications for controlled caveolae trafficking at specific organelles.

\section{Regulation of Caveolae Internalization by Tyrosine Kinases}

The characteristic lipid environment of caveolar invaginations leads to a specific set of membrane proteins including ATP handling enzymes localized to the caveolar membrane. One example is the distribution of $\mathrm{Na} / \mathrm{K}$-ATPase within different plasma membrane domains. A non-pumping $\mathrm{Na} / \mathrm{K}$ ATPase subpopulation is found in caveolae (Wang et al., 2004; Liang et al., 2007). Further, a study revealed the loss of Cav1 and caveolae at the plasma membrane after knockdown of $\mathrm{Na} / \mathrm{K}$-ATPase (Cai et al., 2008). Additional binding studies between purified $\mathrm{Na} / \mathrm{K}$-ATPase and Cav1 as well as cross-linking experiments demonstrated a direct interaction although within a low molar stoichiometry (Yosef et al., 2016; Nie et al., 2020). Knockdown of Na/K-ATPase also resulted in increased Src levels at the plasma membrane (Cai et al., 2008). It was shown previously that the tyrosine kinase Src is able to bind Cav1 leading to phosphorylation of the Cav1 residue tyrosine 14. After phosphorylation, Cav1 disassembles from the plasma membrane and caveolae internalization occurs (Parton et al., 1994; Lee et al., 2001). Several studies identified Cav1 as a substrate for Src which can be activated by various ligands and molecules, e.g., insulin or okadaic acid (Kiss and Botos, 2009), indicating that the phosphorylation of Cav1 plays an important role in caveolae internalization.

Besides Src, the tyrosine kinase $\mathrm{Abl}$ is also able to phosphorylate Cav1 tyrosine 14 in response to oxidative or tension stress (Sanguinetti and Corley Mastick, 2003). Interestingly, $\mathrm{Abl}$ is involved in the crosstalk between caveolae and stress fibers. Thereby, Abl together with the stress fiber regulator mDial (formin homology protein) and the F-BAR protein FBP17 regulates the formation and stabilization of caveolae at the plasma membrane (Echarri et al., 2012, 2019). Replica EM showing the cytosolic side of the plasma membrane (such as in Figure 1) illustrate that caveolae regularly locate in close proximity to actin filaments. Indeed, Filamin A was found to connect Cav1 with actin (Stahlhut and Van Deurs, 2000). Several studies showed that actin filaments are important for Cav1 and caveolae internalization, and that upon disruption of actin polymerization intracellular Cav1 trafficking is impaired (see detailed review, Echarri and Del Pozo, 2015). Additional, Pacsin 2 and EHBP1 contain actin binding domains, and thereby both proteins are able to closely connect actin to caveolar membrane invaginations (Guilherme et al., 2004; Kostan et al., 2014). Of note, both proteins locate at the neck of caveolae suggesting that their actin binding motif might be an important regulator for caveolae mobility.

\section{CONCLUSION AND OUTLOOK}

Caveolae internalization is found in many cells and tissues. Here, we summarized current concepts in caveolae trafficking and its role in physiology. As discussed above, essential steps during the internalization and migration are dependent on ATP or GTP (see also summary Figure 2). In the past, the small size of caveolae made it difficult to monitor their intracellular movements. Therefore, the application of recently developed high resolution live imaging methods will enable the full elucidation of intracellular caveolae trafficking throughout the cell. Novel imaging techniques such as super resolution light imaging and its combination with electron microscopy and tomography will allow for future detailed investigations of the caveolae life cycle and trafficking routes (Taraska, 2019). Also focus-ion beam scanning electron microscopy (FIB-SEM) could help to further dissect intracellular caveolae movement as this technique allows to visualize complete cell volumes in the highest resolution. A correlative approach to identify Caveolin and Cavin positive membranes would help to identify caveolar vesicles in the FIB-SEM stacks.

Of particular interest is the development or identification of caveolae specific cargos and receptors that are only internalized via caveolar endocytosis. This would allow caveolae-specific intracellular routes to be monitored and further identify novel factors involved in these pathways. New techniques for identifying the protein-protein interactions will provide additional insights in caveolae contact sites between various organelles. Finding these caveolae contact sites will help to determine how caveolae are involved in lipid metabolism and diseases. Another largely unexplored aspect in caveolae dynamics is the influence of local ATP/GTP concentrations. These changes can occur due to hypoxia. Indeed, cells growing under low oxygen levels show altered caveolae behavior. In adipocytes, it was observed that loss of oxygen results in decreased Cav1 expression and consequently reduced caveolae number (Regazzetti et al., 2015; Varela-Guruceaga et al., 2018). However, hypoxia in cancer cells and in the colon of the mouse intestine led to increased Cav1 expression (Wang et al., 
2012; Xie et al., 2014; Bourseau-Guilmain et al., 2016). The oxygen sensitive transcription factor hypoxia-inducible factor (HIF1) was assigned to cause the changes in Cav1 gene expression (Wang et al., 2012; Xie et al., 2014; BourseauGuilmain et al., 2016; Varela-Guruceaga et al., 2018). This raises the possibility that caveolae could be sensitive to local ATP/GTP levels due to oxygen and nutrient deficiencies. The impact of low ATP levels on caveolae in cancer cells are of particular interest as caveolae are proposed to be involved in cancer progression. Taken together, energy requirements in caveolae trafficking are an important regulator for cellular metabolism and physiology. The extent of these mechanisms are not yet fully understood. Future work aimed at unraveling these questions will lead to a deeper understanding of the role these small plasma membrane organelles play in both health and disease.

\section{REFERENCES}

Aboulaich, N., Vainonen, J. P., Stralfors, P., and Vener, A. V. (2004). Vectorial proteomics reveal targeting, phosphorylation and specific fragmentation of polymerase I and transcript release factor (PTRF) at the surface of caveolae in human adipocytes. Biochem. J. 383, 237-248. doi: 10.1042/BJ20040647

Antonny, B., Burd, C., De Camilli, P., Chen, E., Daumke, O., Faelber, K., et al. (2016). Membrane fission by dynamin: what we know and what we need to know. EMBO J. 35, 2270-2284. doi: 10.15252/embj.201694613

Ariotti, N., Rae, J., Leneva, N., Ferguson, C., Loo, D., Okano, S., et al. (2015). Molecular characterization of caveolin-induced membrane curvature. J. Biol. Chem. 290, 24875-24890. doi: 10.1074/jbc.M115.644336

Bhattacharyya, S., and Pucadyil, T. J. (2020). Cellular functions and intrinsic attributes of the ATP-binding Eps15 homology domain-containing (EHD) proteins. Protein Sci. 29, 1321-1330. doi: 10.1002/pro.3860

Blouin, C. M., Le Lay, S., Eberl, A., Köfeler, H. C., Guerrera, I. C., Klein, C., et al. (2010). Lipid droplet analysis in caveolin-deficient adipocytes: alterations in surface phospholipid composition and maturation defects. J. Lipid Res. 51, 945-956. doi: 10.1194/jlr.M001016

Botos, E., Klumperman, J., Oorschot, V., Ígyártó, B., Magyar, A., Oláh, M., et al. (2008). Caveolin-1 is transported to multi-vesicular bodies after albumininduced endocytosis of caveolae in HepG2 cells. J. Cell. Mol. Med. 12, 1632-1639. doi: 10.1111/j.1582-4934.2007.00167.x

Boucrot, E., Howes, M. T., Kirchhausen, T., and Parton, R. G. (2011). Redistribution of caveolae during mitosis. J. Cell Sci. 124, 1965-1972. doi: $10.1242 /$ jcs. 076570

Bourseau-Guilmain, E., Menard, J. A., Lindqvist, E., Indira Chandran, V., Christianson, H. C., Cerezo Magaña, M., et al. (2016). Hypoxia regulates global membrane protein endocytosis through caveolin-1 in cancer cells. Nat. Commun. 7:11371. doi: 10.1038/ncomms11371

Bravo-Sagua, R., Parra, V., Ortiz-Sandoval, C., Navarro-Marquez, M., Rodríguez, A. E., Diaz-Valdivia, N., et al. (2019). Caveolin-1 impairs PKA-DRP1-mediated remodelling of ER-mitochondria communication during the early phase of ER stress. Cell Death Differ. 26, 1195-1212. doi: 10.1038/s41418-018-0197-1

Cai, T., Wang, H., Chen, Y., Liu, L., Gunning, W. T., Quintas, L. E. M., et al. (2008). Regulation of caveolin-1 membrane trafficking by the Na/K-ATPase. J. Cell Biol. 182, 1153-1169. doi: 10.1083/jcb.200712022

Cameron, P. L., Ruffin, J. W., Bollag, R., Rasmussen, H., and Cameron, R. S. (1997). Identification of caveolin and caveolin-related proteins in the brain. J. Neurosci. 17, 9520-9535. doi: 10.1523/jneurosci.17-24-09520.1997

Carver, L. A., and Schnitzer, J. E. (2003). Caveolae: mining little caves for new cancer targets. Nat. Rev. Cancer 3, 571-581. doi: 10.1038/nrc1146

Catalán, V., Gómez-Ambrosi, J., Rodríguez, A., Silva, C., Rotellar, F., Gil, M. J., et al. (2008). Expression of caveolin-1 in human adipose tissue is upregulated in obesity and obesity-associated type 2 diabetes

\section{AUTHOR CONTRIBUTIONS}

CM wrote the manuscript and prepared figures. JT commented on and edited the manuscript.

\section{FUNDING}

JT was supported by the Intramural Research Program of the National Heart Lung and Blood Institute, National Institutes of Health.

\section{ACKNOWLEDGMENTS}

All pathway schemes were created with Biorender.com. We thank all members of the Taraska group for critically reading and helpful comments to the manuscript.

mellitus and related to inflammation. Clin. Endocrinol. 68, 213-219. doi: 10.1111/j.1365-2265.2007.03021.x

Cheng, J. P. X., Mendoza-Topaz, C., Howard, G., Chadwick, J., Shvets, E., Cowburn, A. S., et al. (2015). Caveolae protect endothelial cells from membrane rupture during increased cardiac output. J. Cell Biol. 211, 53-61. doi: $10.1083 /$ jcb. 201504042

Cheng, J. P. X., and Nichols, B. J. (2016). Caveolae : one function or many Trends Cell Biol. 26, 177-189. doi: 10.1016/j.tcb.2015.10.010

Chow, B. W., Nuñez, V., Kaplan, L., Granger, A. J., Bistrong, K., Zucker, H. L., et al. (2020). Caveolae in CNS arterioles mediate neurovascular coupling. Nature 579, 106-110. doi: 10.1038/s41586-020-2026-1

Cohen, A. W., Hnasko, R., Schubert, W., and Lisanti, M. P. (2004a). Role of caveolae and caveolins in health and disease. Physiol. Rev. 84, 1341-1379. doi: 10.1152/physrev.00046.2003

Cohen, A. W., Razani, B., Schubert, W., Williams, T. M., Wang, X. B., Iyengar, P., et al. (2004b). Role of caveolin-1 in the modulation of lipolysis and lipid droplet formation. Diabetes 53, 1261-1270. doi: 10.2337/diabetes.53.5.1261

Daumke, O., Lundmark, R., Vallis, Y., Martens, S., Butler, P. J. G., and McMahon, H. T. (2007). Architectural and mechanistic insights into an EHD ATPase involved in membrane remodelling. Nature 449, 923-927. doi: $10.1038 /$ nature 06173

Daumke, O., and Praefcke, G. J. K. (2016). Mechanisms of GTP hydrolysis and conformational transitions in the dynamin superfamily. Biopolymers 105, 580-593. doi: 10.1002/bip.22855

Del Pozo, M. A., Lolo, F.-N., and Echarri, A. (2021). Caveolae: mechanosensing and mechanotransduction devices linking membrane trafficking to mechanoadaptation. Curr. Opin. Cell Biol. 68, 113-123. doi: 10.1016/j.ceb.2020.10.008

Deo, R., Kushwah, M. S., Kamerkar, S. C., Kadam, N. Y., Dar, S., Babu, K., et al. (2018). ATP-dependent membrane remodeling links EHD1 functions to endocytic recycling. Nat. Commun. 9:5187. doi: 10.1038/s41467-018-07586-Z

Dewulf, M., Köster, D. V., Sinha, B., Viaris de Lesegno, C., Chambon, V., Bigot, A., et al. (2019). Dystrophy-associated caveolin-3 mutations reveal that caveolae couple IL6/STAT3 signaling with mechanosensing in human muscle cells. Nat. Commun. 10, 1-13. doi: 10.1038/s41467-019-09405-5

Domingues, L., Hurbain, I., Gilles-Marsens, F., Sirés-Campos, J., André, N., Dewulf, M., et al. (2020). Coupling of melanocyte signaling and mechanics by caveolae is required for human skin pigmentation. Nat. Commun. 11:2988. doi: 10.1038/s41467-020-16738-Z

Echarri, A., and Del Pozo, M. A. (2015). Caveolae - mechanosensitive membrane invaginations linked to actin filaments. J. Cell Sci. 128, 2747-2758. doi: $10.1242 /$ jcs. 153940

Echarri, A., Muriel, O., Pavón, D. M., Azegrouz, H., Escolar, F., Terrón, M. C., et al. (2012). Caveolar domain organization and trafficking is regulated by $\mathrm{Abl}$ kinases and mDia1. J. Cell Sci. 125: 4413. doi: 10.1242/jcs.120816 
Echarri, A., Pavón, D. M., Sánchez, S., García-García, M., Calvo, E., Huerta-López, C., et al. (2019). An Abl-FBP17 mechanosensing system couples local plasma membrane curvature and stress fiber remodeling during mechanoadaptation. Nat. Commun. 10:5828. doi: 10.1038/s41467-019-13782-2

Faelber, K., Posor, Y., Gao, S., Held, M., Roske, Y., Schulze, D., et al. (2011). Crystal structure of nucleotide-free dynamin. Nature 477, 556-562. doi: $10.1038 /$ nature10369

Fagerholm, S., Örtegren, U., Karlsson, M., Ruishalme, I., and Strålfors, P. (2009). Rapid insulin-dependent endocytosis of the insulin receptor by caveolae in primary adipocytes. PLoS ONE 4:e5985. doi: 10.1371/journal.pone.0005985

Fan, G., Kaßmann, M., Cui, Y., Matthaeus, C., Kunz, S., Zhong, C., et al. (2020). Age attenuates the T-type CaV3.2-RyR axis in vascular smooth muscle. Aging Cell 19:e13134. doi: 10.1111/acel.13134

Ferguson, S. M., and De Camilli, P. (2012). Dynamin, a membrane-remodelling GTPase. Nat. Rev. Mol. Cell Biol. 13, 75-88. doi: 10.1038/nrm3266

Fernandez, I., Ying, Y., Albanesi, J., and Anderson, R. G. W. (2002). Mechanism of caveolin filament assembly. Proc. Natl. Acad. Sci. U.S.A. 99, 11193-11198. doi: 10.1073/pnas.172196599

Förstermann, U., and Sessa, W. C. (2012). Nitric oxide synthases: regulation and function. Eur. Heart J. 33, 1-13. doi: 10.1093/eurheartj/ehr304

Foster, C. R., Satomi, S., Kato, Y., and Patel, H. H. (2020). The caveolarmitochondrial interface: regulation of cellular metabolism in physiology and pathophysiology. Biochem. Soc. Trans. 48, 165-177. doi: 10.1042/BST20190388

Frank, P. G., Pavlides, S., and Lisanti, M. P. (2009). Caveolae and transcytosis in endothelial cells : role in atherosclerosis. Cell Tissue Res. 335, 41-47. doi: 10.1007/s00441-008-0659-8

Fridolfsson, H. N., Kawaraguchi, Y., Ali, S. S., Panneerselvam, M., Niesman, I. R., Finley, J. C., et al. (2012). Mitochondria-localized caveolin in adaptation to cellular stress and injury. FASEB J. 26, 4637-4649. doi: 10.1096/fj.12-215798

Fujimoto, T., Kogo, H., Ishiguro, K., Tauchi, K., and Nomura, R. (2001). Caveolin2 is targeted to lipid droplets, a new "membrane domain" in the cell. J. Cell Biol. 152, 1079-1085. doi: 10.1083/jcb.152.5.1079

Gambin, Y., Ariotti, N., McMahon, K.-A., Bastiani, M., Sierecki, E., Kovtun, O., et al. (2014). Single-molecule analysis reveals self assembly and nanoscale segregation of two distinct cavin subcomplexes on caveolae. Elife 3, 1-18. doi: 10.7554/elife.01434

Garcia, J., Bagwell, J., Njaine, B., Norman, J., Levic, D. S., Wopat, S., et al. (2017). Sheath cell invasion and trans-differentiation repair mechanical damage caused by loss of caveolae in the zebrafish notochord. Curr. Biol. 27, 1982-1989.e3. doi: 10.1016/j.cub.2017.05.035

Gazzerro, E., Sotgia, F., Bruno, C., Lisanti, M. P., and Minetti, C. (2010). Caveolinopathies: From the biology of caveolin-3 to human diseases. Eur. J. Hum. Genet. 18, 137-145. doi: 10.1038/ejhg.2009.103

George, M., Ying, G., Rainey, M. A., Solomon, A., Parikh, P. T., Gao, Q., et al. (2007). Shared as well as distinct roles of EHD proteins revealed by biochemical and functional comparisons in mammalian cells and C. elegans. BMC Cell Biol. 8:3. doi: $10.1186 / 1471-2121-8-3$

Golani, G., Ariotti, N., Parton, R. G., and Kozlov, M. M. (2019). Membrane curvature and tension control the formation and collapse of caveolar superstructures. Dev. Cell 48, 523-538.e4. doi: 10.1016/j.devcel.2018.12.005

Graf, G. A., Connell, P. M., Van Der Westhuyzen, D. R., and Smart, E. J. (1999). The class B, type I scavenger receptor promotes the selective uptake of high density lipoprotein cholesterol ethers into caveolae. J. Biol. Chem. 274, 12043-12048. doi: $10.1074 /$ jbc.274.17.12043

Grassart, A., Cheng, A. T., Hong, S. H., Zhang, F., Zenzer, N., Feng, Y., et al. (2014). Actin and dynamin2 dynamics and interplay during clathrin-mediated endocytosis. J. Cell Biol. 205, 721-735. doi: 10.1083/jcb.201403041

Guilherme, A., Soriano, N. A., Furcinitti, P. S., and Czech, M. P. (2004). Role of EHD1 and EHBP1 in perinuclear sorting and insulin-regulated GLUT4 recycling in 3T3-L1 adipocytes. J. Biol. Chem. 279, 40062-40075. doi: 10.1074/jbc.M401918200

Han, B., Copeland, C. A., Kawano, Y., Rosenzweig, E. B., Austin, E. D., Shahmirzadi, L., et al. (2016a). Characterization of a caveolin-1 mutation associated with both pulmonary arterial hypertension and congenital generalized lipodystrophy. Traffic 17, 1297-1312. doi: 10.1111/tra.12452

Han, B., Copeland, C. A., Tiwari, A., and Kenworthy, A. K. (2016b). Assembly and turnover of caveolae: what do we really know? Front. Cell Dev. Biol. 4:68. doi: $10.3389 /$ fcell.2016.00068
Han, B., Porta, J., Hanks, J., Peskova, Y., Binshtein, E., Dryden, K., et al. (2020). Structure and assembly of CAV1 8 S complexes revealed by single particle electron microscopy. Sci. Adv. 6:eabc6185. doi: 10.1101/2020.06.04.133678

Han, Y., Branon, T. C., Martell, J. D., Boassa, D., Shechner, D., Ellisman, M. H., et al. (2019). Directed evolution of split APEX2 peroxidase. ACS Chem. Biol. 14, 619-635. doi: 10.1021/acschembio.8b00919

Hansen, C. G., Howard, G., and Nichols, B. J. (2011). Pacsin 2 is recruited to caveolae and functions in caveolar biogenesis. J. Cell Sci. 124, 2777-2785. doi: $10.1242 /$ jcs.084319

Hansen, C. G., Shvets, E., Howard, G., Riento, K., and Nichols, B. J. (2013). Deletion of cavin genes reveals tissue-specific mechanisms for morphogenesis of endothelial caveolae. Nat. Commun. 4:1831. doi: 10.1038/ncomms2808

Hanson, P. I., Roth, R., Lin, Y., and Heuser, J. E. (2008). Plasma membrane deformation by circular arrays of ESCRT-III protein filaments. J. Cell Biol. 180, 389-402. doi: 10.1083/jcb.200707031

Hao, J. W., Wang, J., Guo, H., Zhao, Y. Y., Sun, H. H., Li, Y. F., et al. (2020). CD36 facilitates fatty acid uptake by dynamic palmitoylation-regulated endocytosis. Nat. Commun. 11, 1-16. doi: 10.1038/s41467-020-18565-8

Hayer, A., Stoeber, M., Bissig, C., and Helenius, A. (2010a). Biogenesis of caveolae: stepwise assembly of large caveolin and cavin complexes. Traffic 11, 361-382. doi: 10.1111/j.1600-0854.2009.01023.x

Hayer, A., Stoeber, M., Ritz, D., Engel, S., Meyer, H. H., and Helenius, A. (2010b). Caveolin-1 is ubiquitinated and targeted to intralumenal vesicles in endolysosomes for degradation. J. Cell Biol. 191, 615-629. doi: $10.1083 /$ jcb.201003086

He, K., Yan, X., Li, N., Dang, S., Xu, L., Zhao, B., et al. (2015). Internalization of the TGF- $\beta$ type I receptor into caveolin-1 and EEA1 double-positive early endosomes. Cell Res. 25, 738-752. doi: 10.1038/cr.2015.60

Henley, J. R., Krueger, E. W. A., Oswald, B. J., and McNiven, M. A. (1998). Dynamin-mediated internalization of caveolae. J. Cell Biol. 141, 85-99. doi: $10.1083 /$ jcb.141.1.85

Henne, W. M. (2020). The molecular era of lipid droplets. Contact 3, 1-9. doi: $10.1177 / 2515256420912090$

Hoernke, M., Mohan, J., Larsson, E., Blomberg, J., Kahra, D., Westenhoff, S., et al. (2017). EHD2 restrains dynamics of caveolae by an ATP-dependent, membrane-bound, open conformation. Proc. Natl. Acad. Sci. U.S.A. 114, E4360-E4369. doi: 10.1073/pnas.1614066114

Hubert, M., Larsson, E., and Lundmark, R. (2020a). Keeping in touch with the membrane; protein- and lipid-mediated confinement of caveolae to the cell surface. Biochem. Soc. Trans. 48, 155-163. doi: 10.1042/BST20190386

Hubert, M., Larsson, E., Venkata, N., Vegesna, G., Ahnlund, M., Johansson, I., et al. (2020b). Lipid accumulation controls the balance between surface connection and scission of caveolae. Elife 9:e55038. doi: 10.7554/eLife.55038

Iversen, T. G., Skretting, G., Van Deurs, B., and Sandvig, K. (2003). Clathrincoated pits with long, dynamin-wrapped necks upon expression of a clathrin antisense RNA. Proc. Natl. Acad. Sci. U.S.A. 100, 5175-5180. doi: 10.1073/pnas.0534231100

Jakobsson, J., Ackermann, F., Andersson, F., Larhammar, D., Low, P., and Brodin, L. (2011). Regulation of synaptic vesicle budding and dynamin function by an EHD ATPase. J. Neurosci. 31, 13972-13980. doi: 10.1523/jneurosci.1289-11.2011

Jansa, P., Mason, S. W., Hoffmann-Rohrer, U., and Grummt, I. (1998) Cloning and functional characterization of PTRF, a novel protein which induces dissociation of paused ternary transcription complexes. EMBO J. 17, 2855-2864. doi: 10.1093/emboj/17.10.2855

Ketteler, J., and Klein, D. (2018). Caveolin-1, cancer and therapy resistance. Int. J. Cancer 143, 2092-2104. doi: 10.1002/ijc.31369

Khater, I. M., Meng, F., Timothy, H. W., and Nabi, I. R. (2018). Super resolution network analysis defines the molecular architecture of caveolae and caveolin-1 scaffolds. Sci. Rep. 8:9009. doi: 10.1038/s41598-01827216-4

Kim, C. A., Delépine, M., Boutet, E., El Mourabit, H., Le Lay, S., Meier, M., et al. (2008). Association of a homozygous nonsense caveolin-1 mutation with berardinelli-seip congenital lipodystrophy. J. Clin. Endocrinol. Metab. 93, 1129-1134. doi: 10.1210/jc.2007-1328

Kiss, A. L., and Botos, E. (2009). Endocytosis via caveolae: alternative pathway with distinct cellular compartments to avoid lysosomal degradation? J. Cell. Mol. Med. 13, 1228-1237. doi: 10.1111/j.1582-4934.2009.00754.x 
Kong, L., Sochacki, K. A., Wang, H., Fang, S., Canagarajah, B., Kehr, A. D., et al. (2018). Cryo-EM of the dynamin polymer assembled on lipid membrane. Nature 560, 258-262. doi: 10.1038/s41586-018-0378-6

Kory, N. Jr, R. V. F., and Walther, T. C. (2016). Targeting fat : mechanisms of protein localization to lipid droplets. Trends Cell Biol. 26, 535-546. doi: 10.1016/j.tcb.2016.02.007

Kostan, J., Salzer, U., Orlova, A., Törö, I., Hodnik, V., Senju, Y., et al. (2014). Direct interaction of actin filaments with F - BAR protein pacsin2. EMBO Rep. 15, 1154-1162. doi: 10.15252/embr.201439267

Kovtun, O., Tillu, V. A., Ariotti, N., Parton, R. G., and Collins, B. M. (2015). Cavin family proteins and the assembly of caveolae. J. Cell Sci. 128, 1269-1278. doi: $10.1242 /$ jcs. 167866

Lamaze, C., Tardif, N., Dewulf, M., Vassilopoulos, S., and Blouin, C. M. (2017). The caveolae dress code: structure and signaling. Curr. Opin. Cell Biol. 47, 117-125. doi: 10.1016/j.ceb.2017.02.014

Lapierre, L. A., Ducharme, N. A., Drake, K. R., Goldenring, J. R., and Kenworthy, A. K. (2012). Coordinated regulation of caveolin-1 and Rab1la in apical recycling compartments of polarized epithelial cells. Exp. Cell Res. 318, 103-113. doi: 10.1016/j.yexcr.2011.10.010

Le Lay, S., Hajduch, E., Lindsay, M. R., Le Lièpvre, X., Thiele, C., Ferré, P., et al. (2006). Cholesterol-induced caveolin targeting to lipid droplets in adipocytes: a role for caveolar endocytosis. Traffic 7, 549-561. doi: 10.1111/j.1600-0854.2006.00406.x

Le Lay, S., and Kurzchalia, T. V. (2005). Getting rid of caveolins: phenotypes of caveolin-deficient animals. Biochim. Biophys. Acta Mol. Cell Res. 1746, 322-333. doi: 10.1016/j.bbamcr.2005.06.001

Le, P. U., and Nabi, I. (2003). Distinct caveolae-mediated endocytic pathways target the Golgi apparatus and the endoplasmic reticulum. J. Cell Sci. 116, 1059-1071. doi: $10.1242 /$ jcs.00327

Lee, H., Park, D. S., Razani, B., Russell, R. G., Pestell, R. G., and Lisanti, M. P. (2002). Caveolin-1 mutations (P132L and null) and the pathogenesis of breast cancer: Caveolin-1 (P132L) behaves in a dominant-negative manner and caveolin-1 (-/-) null mice show mammary epithelial cell hyperplasia. Am. J. Pathol. 161, 1357-1369. doi: 10.1016/S0002-9440(10)64412-4

Lee, H., Woodman, S. E., Engelman, J. A., Volonte, D., Galbiati, F., Kaufman, H. L., et al. (2001). Palmitoylation of caveolin-1 at a single site (Cys-156) controls its coupling to the c-Src tyrosine kinase: targeting of dually acylated molecules (gpi-linked, transmembrane, or cytoplasmic) to caveolae effectively uncouples c-src and caveolin-1 (Tyr-14). J. Biol. Chem. 276, 35150-35158. doi: 10.1074/jbc.M104530200

Li, W. P., Liu, P., Pilcher, B. K., and Anderson, R. G. W. (2001). Cellspecific targeting of caveolin-1 to caveolae, secretory vesicles, cytoplasm or mitochondria. J. Cell Sci. 114, 1397-1408. doi: 10.1242/jcs.01420

Li, Z., Schulze, R. J., Weller, S. G., Krueger, E. W., Schott, M. B., Zhang, X., et al. (2016). A novel Rab10-EHBP1-EHD2 complex essential for the autophagic engulfment of lipid droplets. Sci. Adv. 2:e1601470. doi: 10.1126/sciadv.1601470

Lian, X., Matthaeus, C., Kaßmann, M., Daumke, O., and Gollasch, M. (2019). Pathophysiological role of caveolae in hypertension. Front. Med. 6:153. doi: 10.3389/fmed.2019.00153

Liang, M., Tian, J., Liu, L., Pierre, S., Liu, J., Shapiro, J., et al. (2007). Identification of a pool of non-pumping Na/K-ATPase. J. Biol. Chem. 282, 10585-10593. doi: 10.1074/jbc.M609181200

Lim, Y.-W., Lo, H. P., Ferguson, C., Martel, N., Giacomotto, J., Gomez, G. A., et al. (2017). Caveolae protect notochord cells against catastrophic mechanical failure during development. Curr. Biol. 27, 1968-1981.e7. doi: 10.1016/j.cub.2017.05.067

Liu, L., and Pilch, P. F. (2016). PTRF/Cavin-1 promotes efficient ribosomal RNA transcription in response to metabolic challenges. Elife 5, 1-20. doi: 10.7554/elife.17508

Ludwig, A., Howard, G., Mendoza-Topaz, C., Deerinck, T., Mackey, M., Sandin, S., et al. (2013). Molecular composition and ultrastructure of the caveolar coat complex. PLoS Biol. 11:e1001640. doi: 10.1371/journal.pbio.1001640

Ludwig, A., Nichols, B. J., and Sandin, S. (2016). Architecture of the caveolar coat complex. J. Cell Sci. 129, 3077-3083. doi: 10.1242/jcs.191262

Martinez-Outschoorn, U. E., Sotgia, F., and Lisanti, M. P. (2015). Caveolae and signalling in cancer. Nat. Rev. Cancer 15, 225-237. doi: 10.1038/nrc3915

Matthaeus, C., Lahmann, I., Kunz, S., Jonas, W., Melo, A. A., Lehmann, M., et al. (2020). EHD2-mediated restriction of caveolar dynamics regulates cellular fatty acid uptake. Proc. Natl. Acad. Sci. U.S.A. 117, 7471-7481. doi: 10.1073/pnas.1918415117

Matthaeus, C., Lian, X., Kunz, S., Lehmann, M., Zhong, C., Bernert, C., et al. (2019). ENOS-NO-induced small blood vessel relaxation requires EHD2-dependent caveolae stabilization. PLoS ONE 14:e0223620. doi: 10.1371/journal.pone.0223620

Mayor, S., Parton, R. G., and Donaldson, J. G. (2014). Clathrin-independent pathways of endocytosis. Cold Spring Harb. Perspect. Biol. 6:a016758. doi: 10.1101/cshperspect.a016758

McMahon, K.-A., Wu, Y., Gambin, Y., Sierecki, E., Tillu, V. A., Hall, T., et al. (2019). Identification of intracellular cavin target proteins reveals cavin-PPlalpha interactions regulate apoptosis. Nat. Commun. 10:3279. doi: 10.1038/s41467-019-11111-1

McMahon, K. A., Zhu, M., Kwon, S. W., Liu, P., Zhao, Y., and Anderson, R. G. W. (2006). Detergent-free caveolae proteome suggests an interaction with ER and mitochondria. Proteomics 6, 143-152. doi: 10.1002/pmic.200500208

Melo, A. A., Hegde, B. G., Shah, C., Larsson, E., Isas, J. M., Kunz, S., et al. (2017). Structural insights into the activation mechanism of dynamin-like EHD ATPases. Proc. Natl. Acad. Sci. U.S.A. 114, 5629-5634. doi: 10.1073/pnas.1614075114

Minshall, R. D., Tiruppathi, C., Vogel, S. M., Niles, W. D., Gilchrist, A., Hamm, H. E., et al. (2000). Endothelial cell-surface gp60 activates vesicle formation and trafficking via G(i)-coupled Src kinase signaling pathway. J. Cell Biol. 150, 1057-1069. doi: 10.1083/jcb.150.5.1057

Morén, B., Hansson, B., Negoita, F., Fryklund, C., Lundmark, R., Göransson, O., et al. (2019). EHD2 regulates adipocyte function and is enriched at cell surface-associated lipid droplets in primary human adipocytes. Mol. Biol. Cell 30, 1147-1159. doi: 10.1091/mbc.e18-10-0680

Morén, B., Shah, C., Howes, M. T., Schieber, N. L., McMahon, H. T., Parton, R. G., et al. (2012). EHD2 regulates caveolar dynamics via ATP-driven targeting and oligomerization. Mol. Biol. Cell 23, 1316-1329. doi: 10.1091/mbc.E11-09-0787

Morlot, S., Galli, V., Klein, M., Chiaruttini, N., Manzi, J., Humbert, F., et al. (2012). Membrane shape at the edge of the dynamin helix sets location and duration of the fission reaction. Cell 151, 619-629. doi: 10.1016/j.cell.2012.09.017

Naslavsky, N., and Caplan, S. (2011). EHD proteins: key conductors of endocytic transport. Trends Cell Biol. 21, 122-131. doi: 10.1016/j.tcb.2010.10.003

Navarro, G., Borroto-Escuela, D. O., Fuxe, K., and Franco, R. (2014). Potential of caveolae in the therapy of cardiovascular and neurological diseases. Front. Physiol. 5:370. doi: 10.3389/fphys.2014.00370

Nichols, B. J. (2002). A distinct class of endosome mediates clathrinindependent endocytosis to the Golgi complex. Nat. Cell Biol. 4, 374-378. doi: $10.1038 /$ ncb787

Nie, Y., Bai, F., Chaudhry, M. A., Pratt, R., Shapiro, J. I., and Liu, J. (2020). The $\mathrm{Na} / \mathrm{K}$-ATPase $\alpha 1$ and $\mathrm{c}$-Src form signaling complex under native condition: a crosslinking approach. Sci. Rep. 10, 1-14. doi: 10.1038/s41598-02061920-4

Oh, P., Horner, T., Witkiewicz, H., and Schnitzer, J. E. (2012). Endothelin induces rapid, dynamin-mediated budding of endothelial caveolae rich in ET-B. J. Biol. Chem. 287, 17353-17362. doi: 10.1074/jbc.M111. 338897

Oh, P., McIntosh, D. P., and Schnitzer, J. E. (1998). Dynamin at the neck of caveolae mediates their budding to form transport vesicles by GTP-driven fission from the plasma membrane of endothelium. J. Cell Biol. 141, 101-114. doi: $10.1083 /$ jcb.141.1.101

Olzmann, J. A., and Carvalho, P. (2019). Dynamics and functions of lipid droplets. Nat. Rev. Mol. Cell Biol. 20, 137-155. doi: 10.1038/s41580-018-0085-Z

Ostermeyer, A. G., Paci, J. M., Zeng, Y., Lublin, D. M., Munro, S., and Brown, D. A. (2001). Accumulation of caveolin in the endoplasmic reticulum redirects the protein to lipid storage droplets. J. Cell Biol. 152, 1071-1078. doi: $10.1083 /$ jcb.152.5.1071

Ostermeyer, A. G., Ramcharan, L. T., Zeng, Y., Lublin, D. M., and Brown, D. A. (2004). Role of the hydrophobic domain in targeting caveolin-1 to lipid droplets. J. Cell Biol. 164, 69-78. doi: 10.1083/jcb.200303037

Parton, R. G. (2003). Caveolae-from ultrastructure to molecular mechanisms. Nat. Rev. Mol. Cell Biol. 4, 162-167. doi: 10.1038/nrm1017

Parton, R. G., and Del Pozo, M. A. (2013). Caveolae as plasma membrane sensors, protectors and organizers. Nat. Rev. Mol. Cell Biol. 14, 98-112. doi: $10.1038 / \mathrm{nrm} 3512$ 
Parton, R. G., del Pozo, M. A., Vassilopoulos, S., Nabi, I. R., Le Lay, S., Lundmark, R., et al. (2020a). Caveolae: the FAQs. Traffic 21, 181-185. doi: $10.1111 /$ tra. 12689

Parton, R. G., and Howes, M. T. (2010). Revisiting caveolin trafficking: the end of the caveosome. J. Cell Biol. 191, 439-441.

Parton, R. G., Joggerst, B., and Simons, K. (1994). Regulated internalization of caveolae. J. Cell Biol. 127, 1199-1215. doi: 10.1083/jcb.127.5.1199

Parton, R. G., Kozlov, M. M., and Ariotti, N. (2020b). Caveolae and lipid sorting: shaping the cellular response to stress. J. Cell Biol. 219, 1-13. doi: $10.1083 /$ jcb. 201905071

Parton, R. G., McMahon, K. A., and Wu, Y. (2020c). Caveolae: formation, dynamics, and function. Curr. Opin. Cell Biol. 65, 8-16. doi: 10.1016/j.ceb.2020.02.001

Parton, R. G., Tillu, V. A., and Collins, B. M. (2018). Caveolae. Curr. Biol. 28, R402-R405. doi: 10.1016/j.cub.2017.11.075

Pekar, O., Benjamin, S., Weidberg, H., Smaldone, S., Ramirez, F., and Horowitz, M. (2012). EHD2 shuttles to the nucleus and represses transcription. Biochem. J. 444, 383-394. doi: 10.1042/BJ20111268

Pelkmans, L., Bürli, T., Zerial, M., and Helenius, A. (2004). Caveolin-stabilized membrane domains as multifunctional transport and sorting devices in endocytic membrane traffic. Cell 118, 767-780. doi: 10.1016/j.cell.2004.09.003

Pelkmans, L., Kartenback, J., and Helenius, A. (2001). Caveolar endocytosis of Simian virus 40 reveals a novel two-step vesicular transport pathway to the ER. Nat. Cell Biol. 3, 473-483. doi: 10.1038/35074539

Pelkmans, L., and Zerial, M. (2005). Kinase-regulated quantal assemblies and kissand-run recycling of caveolae. Nature 436, 128-133. doi: 10.1038/nature03866

Pilch, P. F., and Liu, L. (2011). Fat caves: caveolae, lipid trafficking and lipid metabolism in adipocytes. Trends Endocrinol. Metab. 22, 318-324. doi: 10.1016/j.tem.2011.04.001

Pilch, P. F., Meshulam, T., Ding, S., and Liu, L. (2011). Caveolae and lipid trafficking in adipocytes. Clin. Lipidol. 6, 49-58. doi: 10.2217/clp.10.80

Platonova, E., Winterflood, C. M., Junemann, A., Albrecht, D., Faix, J., and Ewers, H. (2015). Single-molecule microscopy of molecules tagged with GFP or RFP derivatives in mammalian cells using nanobody binders. Methods 88, 89-97. doi: 10.1016/j.ymeth.2015.06.018

Pohl, U., Smith, J. S., Tachibana, I., Ueki, K., Lee, H. K., Ramaswamy, S., et al. (2000). EHD2, EHD3, and EHD4 encode novel members of a highly conserved family of EH domain-containing proteins. Genomics 63, 255-262. doi: 10.1006/geno.1999.6087

Pol, A., Luetterforst, R., Lindsay, M., Heino, S., Ikonen, E., and Parton, R. G. (2001). A caveolin dominant negative mutant associates with lipid bodies and induces intracellular cholesterol imbalance. J. Cell Biol. 152, 1057-1070. doi: $10.1083 /$ jcb.152.5.1057

Pol, A., Martin, S., Fernandez, M., Ferguson, C., Carozzi, A., Luetterforst, R., et al. (2004). Dynamic and regulated association of caveolin with lipid bodies: modulation of lipid body motility and function by a dominant negative mutant. Mol. Biol. Cell 15, 99-110. doi: 10.1091/mbc.E03

Pol, A., Morales-paytuv, F., Bosch, M., and Parton, R. G. (2020). Noncaveolar caveolins - duties outside the caves. J. Cell Sci. 133:jcs241562. doi: $10.1242 /$ jcs. 241562

Popescu, L. M., Gherghiceanu, M., Mandache, E., and Cretoiu, D. (2006). Caveolae in smooth muscles: nanocontacts. J. Cell. Mol. Med. 10, 960-990. doi: 10.1111/j.1582-4934.2006.tb00539.x

Predescu, D. N., Neamu, R., Bardita, C., Wang, M., and Predescu, S. A. (2012). Impaired caveolae function and upregulation of alternative endocytic pathways induced by experimental modulation of intersectin-1s expression in mouse lung endothelium. Biochem. Res. Int. 2012:672705. doi: 10.1155/2012/672705

Predescu, S., Predescu, D., Timblin, B., Stan, R., and Mailik, A. (2003). Intersectin regulates fission and internalization of caveolae in endothelial cells. Mol. Biol. Cell 14, 4997-5010. doi: 10.1091/mbc.E03-01-0041

Regazzetti, C., Dumas, K., Lacas-Gervais, S., Pastor, F., Peraldi, P., Bonnafous, S., et al. (2015). Hypoxia inhibits cavin-1 and cavin-2 expression and down-regulates caveolae in adipocytes. Endocrinology 156, 789-801. doi: 10.1210/en.2014-1656

Richter, T., Floetenmeyer, M., Ferguson, C., Galea, J., Goh, J., Lindsay, M. R., et al. (2008). High-resolution 3D quantitative analysis of caveolar ultrastructure and caveola-cytoskeleton interactions. Traffic 9, 893-909. doi: $10.1111 /$ j.1600-0854.2008.00733.x
Root, K. T., Julien, J. A., and Glover, K. J. (2019). Secondary structure of caveolins: a mini review. Biochem. Soc. Trans. 47, 1489-1498. doi: 10.1042/BST20190375

Rossman, J. S., and Lamb, R. A. (2013). Viral membrane scission. Annu. Rev. Cell Dev. Biol. 29, 551-569. doi: 10.1146/annurev-cellbio-101011-155838

Sanguinetti, A. R., and Corley Mastick, C. (2003). c-Abl is required for oxidativeand hyperosmotic-stress-induced tyrosine phosphorylation of caveolin-1. Cell. Signal. 15, 289-298. doi: 10.1016/s0898-6568(02)00090-6

Sathe, M., Muthukrishnan, G., Rae, J., Disanza, A., Thattai, M., Scita, G., et al. (2018). Small GTPases and BAR domain proteins regulate branched actin polymerisation for clathrin and dynamin-independent endocytosis. Nat. Commun. 9, 1-16. doi: 10.1038/s41467-018-03955-w

Schnitzer, J. E., Liu, J., and Oh, P. (1995). Endothelial caveolae have the molecular transport machinery for vesicle budding, docking, and fusion including VAMP, NSF, SNAP, annexins, and GTPases. J. Biol. Chem. 270, 14399-14404. doi: $10.1074 /$ jbc.270.24.14399

Schnitzer, J. E., Oh, P., and Mcintosh, D. P. (1996). Role of GTP hydrolysis in fission of caveolae directly from plasma membranes. Science 274, 239-242.

Schrauwen, I., Szelinger, S., Siniard, A. L., Kurdoglu, A., Corneveaux, J. J., Malenica, I., et al. (2015). A frame-shift mutation in CAV1 is associated with a severe neonatal progeroid and lipodystrophy syndrome. PLOS ONE 10:e0131797. doi: 10.1371/journal.pone.0131797

Seemann, E., Sun, M., Krueger, S., Tröger, J., Hou, W., Haag, N., et al. (2017) Deciphering caveolar functions by syndapin III KO-mediated impairment of caveolar invagination. Elife 6, 1-37. doi: 10.7554/eLife.29854

Senju, Y., Itoh, Y., Takano, K., Hamada, S., and Suetsugu, S. (2011). Essential role of PACSIN2/syndapin-II in caveolae membrane sculpting. J. Cell Sci. 124, 2032-2040. doi: 10.1242/jcs.086264

Senju, Y., Rosenbaum, E., Shah, C., Hamada-Nakahara, S., Itoh, Y., Yamamoto, K., et al. (2015). Phosphorylation of PACSIN2 by protein kinase $C$ triggers the removal of caveolae from the plasma membrane. J. Cell Sci. 128, 2766-2780. doi: $10.1242 /$ jcs. 167775

Shah, C., Hegde, B. G., Morén, B., Behrmann, E., Mielke, T., Moenke, G., et al. (2014). Structural insights into membrane interaction and caveolar targeting of dynamin-like EHD2. Structure 22, 409-420. doi: 10.1016/j.str.2013. 12.015

Shajahan, A. N., Timblin, B. K., Sandoval, R., Tiruppathi, C., Malik, A. B., and Minshall, R. D. (2004). Role of Src-induced dynamin2 phosphorylation in caveolae-mediated endocytosis in endothelial cells. J. Biol. Chem. 279, 20392-20400. doi: 10.1074/jbc.M3087 10200

Shvets, E., Bitsikas, V., Howard, G., Hansen, C. G., and Nichols, B. J. (2015). Dynamic caveolae exclude bulk membrane proteins and are required for sorting of excess glycosphingolipids. Nat. Commun. 6:6867. doi: 10.1038/ncomms7867

Sinha, B., Köster, D., Ruez, R., Gonnord, P., Bastiani, M., Abankwa, D., et al. (2011). Cells respond to mechanical stress by rapid disassembly of caveolae. Cell 144, 402-413. doi: 10.1016/j.cell.2010.12.031

Souto, R. P., Vallega, G., Wharton, J., Vinten, J., Tranum-Jensen, J., and Pilch, P. F. (2003). Immunopurification and characterization of rat adipocyte caveolae suggest their dissociation from insulin signaling. J. Biol. Chem. 278, 18321-18329. doi: 10.1074/jbc.M211541200

Stahlhut, M., and Van Deurs, B. (2000). Identification of filamin as a novel ligand for caveolin-1: evidence for the organization of caveolin-1-associated membrane domains by the actin cytoskeleton. Mol. Biol. Cell 11, 325-337. doi: $10.1091 / \mathrm{mbc} \cdot 11.1 .325$

Stenmark, H. (2009). Rab GTPases as coordinators of vesicle traffic. Nat. Rev. Mol. Cell Biol. 10, 513-525. doi: 10.1038/nrm 2728

Stoeber, M., Schellenberger, P., Siebert, C. A., Leyrat, C., Helenius, A., and Grünewald, K. (2016). Model for the architecture of caveolae based on a flexible, net-like assembly of Cavin 1 and Caveolin discs. Proc. Natl. Acad. Sci. U.S.A. 113, E8069-E8078. doi: 10.1073/pnas.1616838113

Stoeber, M., Stoeck, I. K., Hänni, C., Bleck, C. K. E., Balistreri, G., and Helenius, A. (2012). Oligomers of the ATPase EHD2 confine caveolae to the plasma membrane through association with actin. EMBO J. 31, 2350-2364. doi: 10.1038/emboj.2012.98

Storey, S. M., McIntosh, A. L., Senthivinayagam, S., Moon, K. C., and Atshaves, B. P. (2011). The phospholipid monolayer associated with perilipin-enriched lipid droplets is a highly organized rigid membrane structure. Am. J. Physiol. Endocrinol. Metab. 301, 991-1003. doi: 10.1152/ajpendo.00109.2011 
Sztalryd, C., and Brasaemle, D. L. (2017). The perilipin family of lipid droplet proteins: gatekeepers of intracellular lipolysis. Biochim. Biophys. Acta 1862, 1221-1232. doi: 10.1016/j.bbalip.2017.07.009

Tachikawa, M., Morone, N., Senju, Y., Sugiura, T., and Hanawa,-, K. (2017). Measurement of caveolin-1 densities in the cell membrane for quantification of caveolar deformation after exposure to hypotonic membrane tension. Sci. Rep. 7, 1-14. doi: 10.1038/s41598-017-08259-5

Tagawa, A., Mezzacasa, A., Hayer, A., Longatti, A., Pelkmans, L., and Helenius, A. (2005). Assembly and trafficking of caveolar domains in the cell: caveolae as stable, cargo-triggered, vesicular transporters. J. Cell Biol. 170, 769-779. doi: $10.1083 /$ jcb. 200506103

Takei, K., McPherson, P. S., Schmid, S. L., and De Camilli, P. (1995). Tubular membrane invaginations coated by dynamin rings are induced by GTP- $\gamma S$ in nerve terminals. Nature 374, 186-190. doi: 10.1038/374186a0

Taraska, J. W. (2019). A primer on resolving the nanoscale structure of the plasma membrane with light and electron microscopy. J. Gen. Physiol. 151, 974-985. doi: 10.1085/jgp.201812227

Thiam, A. R., and Dugail, I. (2019). Lipid droplet-membrane contact sites - From protein binding to function. J. Cell Sci. 132:jcs230169. doi: 10.1242/jcs.230169

Torrino, S., Shen, W. W., Blouin, C. M., Mani, S. K., Lesegno, C. V., De, and Bost, P. (2018). EHD2 is a mechanotransducer connecting caveolae dynamics with gene transcription. J. Cell Biol. 217, 4092-4105. doi: 10.1083/jcb.201801122

Traut, T. W. (1994). Physiological concentrations of purines and pyrimidines. Mol. Cell. Biochem. 140, 1-22. doi: 10.1007/BF00928361

Varela-Guruceaga, M., Milagro, F. I., Martínez, J. A., and de Miguel, C. (2018). Effect of hypoxia on caveolae-related protein expression and insulin signaling in adipocytes. Mol. Cell. Endocrinol. 473, 257-267. doi: $10.1016 /$ j.mce.2018.01.026

Walther, T. C., and Farese, R. V. (2009). The life of lipid droplets. Biochim. Biophys. Acta 1791, 459-466. doi: 10.1016/j.bbalip.2008.10.009

Wang, H., Haas, M., Liang, M., Cai, T., Tian, J., Li, S., et al. (2004). Ouabain assembles signaling cascades through the caveolar $\mathrm{Na}+/ \mathrm{K}+$-ATPase. J. Biol. Chem. 279, 17250-17259. doi: 10.1074/jbc.M313239200

Wang, Y., Roche, O., Xu, C., Moriyama, E. H., Heir, P., Chung, J., et al. (2012). Hypoxia promotes ligand-independent EGF receptor signaling via hypoxiainducible factor-mediated upregulation of caveolin-1. Proc. Natl. Acad. Sci. U.S.A. 109, 4892-4897. doi: 10.1073/pnas.1112129109

Webb, A., Francis, C., Webb, J., Kincross, H., Lundy, K., Judson, R., et al. (2020). EHBP1 and EHD2 regulate Dll4 caveolin-mediated endocytosis during blood vessel development. bioRxiv [Preprint]. doi: 10.1101/2020.05.19.104547

Wypijewski, K. J., Tinti, M., Chen, W., Lamont, D., Ashford, M. L. J., Calaghan, S. C., et al. (2015). Identification of caveolar resident proteins in ventricular myocytes using a quantitative proteomic approach: dynamic changes in caveolar composition following adrenoceptor activation. Mol. Cell. Proteomics 14, 596-608. doi: 10.1074/mcp.m114.038570

Xie, L., Xue, X., Taylor, M., Ramakrishnan, S. K., Nagaoka, K., Hao, C., et al. (2014). Hypoxia-inducible factor/MAZ-dependent induction of caveolin-1 regulates colon permeability through suppression of occludin, leading to hypoxia-induced inflammation. Mol. Cell. Biol. 34, 3013-3023. doi: $10.1128 / \mathrm{mcb} .00324-14$

Xing, Y., Wen, Z., Gao, W., Lin, Z., Zhong, J., and Jiu, Y. (2020). Multifaceted functions of host cell, caveolae/caveolin-1 in virus infections yifan. Viruses 12, 1-24. doi: 10.3390/v12050487

Yan, S., Wang, Y., Zhang, Y., Wang, L., Zhao, X., Du, C., et al. (2019). Synaptotagmin-11 regulates the functions of caveolae and responds to mechanical stimuli in astrocytes. FASEB J. 34, 2609-2624. doi: 10.1096/fj.201901715r

Yao, Q., Chen, J., Cao, H., Orth, J. D., McCaffery, J. M., Stan, R. V., et al. (2005). Caveolin-1 interacts directly with dynamin-2. J. Mol. Biol. 348, 491-501. doi: 10.1016/j.jmb.2005.02.003

Yeow, I., Howard, G., Chadwick, J., Mendoza-topaz, C., Hansen, C. G., Nichols, B. J., et al. (2017). Article EHD proteins cooperate to generate caveolar clusters and to maintain caveolae during repeated article EHD proteins cooperate to generate caveolar clusters and to maintain caveolae during repeated mechanical stress. Curr. Biol. 27, 1-12. doi: 10.1016/j.cub.2017. 07.047

Yosef, E., Katz, A., Peleg, Y., Mehlman, T., and Karlish, S. J. D. (2016). Do Src kinase and caveolin interact directly with Na,K-ATPase? J. Biol. Chem. 291, 11736-11750. doi: 10.1074/jbc.M116.721084

Zhou, Y., Ariotti, N., Rae, J., Liang, H., Tillu, V., Tee, S., et al. (2020). Dissecting the nanoscale lipid profile of caveolae. bioRxiv [Preprint]. doi: 10.1101/2020.01.16. 909408

Conflict of Interest: The authors declare that the research was conducted in the absence of any commercial or financial relationships that could be construed as a potential conflict of interest.

Copyright (๑) 2021 Matthaeus and Taraska. This is an open-access article distributed under the terms of the Creative Commons Attribution License (CC BY). The use, distribution or reproduction in other forums is permitted, provided the original author(s) and the copyright owner(s) are credited and that the original publication in this journal is cited, in accordance with accepted academic practice. No use, distribution or reproduction is permitted which does not comply with these terms. 